\title{
Viability of 'Candidatus Liberibacter asiaticus' Prolonged by Addition of Citrus Juice to Culture Medium
}

\author{
Jennifer K. Parker, Sarah R. Wisotsky, Evan G. Johnson, Faraj M. Hijaz, \\ Nabil Killiny, Mark E. Hilf, and Leonardo De La Fuente
}

First and seventh authors: Department of Entomology and Plant Pathology, and second author: Department of Biological Sciences, Auburn University, Auburn, AL; third, fourth, and fifth authors: Citrus Research and Education Center, University of Florida, Lake Alfred, FL; and sixth author: U.S. Horticultural Research Laboratory, United States Department of Agriculture-Agricultural Research Service, Fort Pierce, FL.

Accepted for publication 2 July 2013.

\begin{abstract}
Parker, J. K., Wisotsky, S. R., Johnson, E. G., Hijaz, F. M., Killiny, N., Hilf, M. E., and De La Fuente, L. 2014. Viability of 'Candidatus Liberibacter asiaticus' prolonged by addition of citrus juice to culture medium. Phytopathology 104:15-26.

Huanglongbing, or citrus greening disease, is associated with infection by the phloem-limited bacterium 'Candidatus Liberibacter asiaticus'. Infection with ' $C a$. L. asiaticus' is incurable; therefore, knowledge regarding ' $\mathrm{Ca}$. L. asiaticus' biology and pathogenesis is essential to develop a treatment. However, ' $\mathrm{Ca}$. L. asiaticus' cannot currently be successfully cultured, limiting its study. To gain insight into the conditions conducive for growth of ' $\mathrm{Ca}$. $\mathrm{L}$. asiaticus' in vitro, ' $\mathrm{Ca}$. L. asiaticus' inoculum obtained from seed of fruit from infected pomelo trees (Citrus

was monitored for up to 2 months using quantitative polymerase chain reaction in conjunction with ethidium monoazide. Media tested included one-third King's B (K), K with $50 \%$ juice from the infected fruit, $\mathrm{K}$ with $50 \%$ commercially available grapefruit juice, and $100 \%$ commercially available grapefruit juice. Results show that juice-containing media dramatically prolong viability compared with $\mathrm{K}$ in experiments reproduced during 2 years using different juice sources. Furthermore, biofilm formed at the air-liquid interface of juice cultures contained ' $C a$. L. asiaticus' cells, though next-generation sequencing indicated that other bacterial genera were predominant. Chemical characterization of the media was conducted to discuss possible factors sustaining ' $\mathrm{Ca}$. L. asiaticus' viability in vitro, which will contribute to future development of a culture medium for ' $\mathrm{Ca}$. L. asiaticus'.
\end{abstract} maxima 'Mato Buntan') was added to different media, and cell viability
Huanglongbing (HLB), also known as citrus greening disease, is a disease of citrus which affects citrus crops in Asia, Africa, the Arabian Peninsula, Brazil, and, most recently, the United States $(3,17)$. Fruit from trees infected with HLB can be immature, misshapen, or bitter, and the productive lifespan of an infected tree is dramatically reduced. Currently, there is no known treatment or cure for HLB. Unknown in the United States prior to its detection in Florida in 2005, HLB has spread rapidly through much of Florida and has also been detected in several other states, recently including Texas and California (48). The suspected causal agent of HLB in the United States is the phloem-limited bacterium 'Candidatus Liberibacter asiaticus', though different proposed species (' $\mathrm{Ca}$. L. africanus' and ' $\mathrm{Ca}$. L. americanus') are associated with the disease in other regions of the world $(3,17)$. To assist with efforts to develop a treatment or cure for HLB, it is crucial that the suspected causal agent be successfully cultured under laboratory conditions to aid in its study; however, a reliable method for ' $\mathrm{Ca}$. L. spp.' culture has not yet been developed.

Several efforts have been made to culture ' $\mathrm{Ca}$. L. asiaticus,' none of which have been entirely successful or reproducible. One attempt to isolate ' $\mathrm{Ca}$. L. asiaticus' in pure culture using a medium designed for a related bacterium resulted in the co-culture of 'Ca. L. asiaticus' and an actinobacterium related to Propionibacterium acnes (9). Though P. acnes is a typically commensal

Corresponding author: L. De La Fuente; E-mail address: 1zd0005@auburn.edu

* The $e$-Xtra logo stands for "electronic extra" and indicates that the online version contains two supplemental figures. Figure 6 appears in color online.

http://dx.doi.org/10.1094/PHYTO-05-13-0119-R

(c) 2014 The American Phytopathological Society member of human skin flora and, thus, was likely introduced to the culture via handling contamination (52), this co-culture may be indicative of the need of ' $\mathrm{Ca}$. L. asiaticus' to obtain additional nutrients, chemical signals, or some other environmental modifications through a mutualistic relationship with another bacterium to grow efficiently in vitro. Most recently, the medium Liber A was described for the growth of all three proposed Liberibacter spp. associated with HLB (42). As reported by the authors, colonies were observed on solid medium after 3 to 4 days, and viability was lost after four to five serial colony transfers (each with duration of 10 to 14 days). In liquid medium, cells clumps were visible after 7 to 10 days. The carbon source in Liber A medium is citrus vein extract (CVE), prepared by filter sterilizing blended sections of petioles and midveins from young citrus leaves. Though this approach is ostensibly the most successful to date for culturing ' $\mathrm{Ca}$. L. spp.', the fact that the medium is based on a complicated extraction of nutrients from plant material implies that reproducibility of the media composition will be difficult. Accordingly, no other research has been published using Liber A as a culture medium. Furthermore, this approach yields a nondurable culture (17), which indicates that, even if a standardized CVE were available, the culture method is still insufficient.

Due to the need for a more robust, reproducible culture method, the current study was conducted to explore conditions that might contribute to prolonged ' $C a$. L. asiaticus' cell viability. It was previously demonstrated that quantitative polymerase chain reaction (qPCR) in conjunction with ethidium monoazide (EMA) can be used to determine the viability of ' $\mathrm{Ca}$. L. asiaticus' cells (51). Therefore, this method was employed to determine ' $\mathrm{Ca}$. L. asiaticus' cell viability over time in different culture media. It was 
hypothesized that prolonged cell viability in a certain medium should be indicative of a nutritional or environmental preference for that medium over another. For this study, citrus fruit seed from trees infected with ' $\mathrm{Ca}$. L. asiaticus' were macerated to create a ' $C a$. L. asiaticus' inoculum which was used to inoculate various culture media. A dilute nutrient medium was selected as a control medium, and it was supplemented with various types and concentrations of citrus fruit juice to produce the experimental media. Inoculated media were then monitored over time by qPCR-EMA for total and viable cells. Results indicate that citrus fruit juice prolongs viability of ' $\mathrm{Ca}$. L. asiaticus', allowing it to survive in biofilm and planktonic fractions for several months in culture with other microflora. The sustained viability presented here, which was reproduced with different citrus juice preparations and inoculum sources over 2 years, suggests that growth of ' $\mathrm{Ca}$. L. asiaticus' in vitro may be possible and deserves further consideration.

\section{MATERIALS AND METHODS}

' $\boldsymbol{C a}$. L. asiaticus' inoculum preparation. Pomelo fruit (Citrus maxima 'Mato Buntan') were collected from a single tree in Fort Pierce, FL (April 2011 to September 2012), and samples from an additional variety ('Liane') were also collected from a single tree in September 2012. Both trees were known to be infected with 'Ca. L. asiaticus' since at least spring 2010 based on qPCR analyses (K. Sims, personal communication). Fruit were shipped overnight to Auburn University, Alabama, where experiments commenced $\approx 24 \mathrm{~h}$ after sample collection. Entire seed from the fruit were used to create a ' $C a$. L. asiaticus' inoculum. Fruit were surface sterilized with $1.2 \%$ sodium hypochlorite solution followed by $70 \%$ ethanol solution. All seed from a fruit were collected aseptically and weighed. Seed were then placed in two to four autoclaved, sterile KLECO canisters (Kinetic Laboratory Equipment Co., Visalia, CA) with $3 \mathrm{ml}$ of a one-third dilution of King's B media (K) (24) per canister and pulverized for 2 min in a KLECO 4200 ball mill. Seed paste was then scraped into two sterile 50-ml conical tubes, and $35 \mathrm{ml}$ of $\mathrm{K}$ was added to each. After thorough vortexing, the seed slurries were filtered through a $100-\mu \mathrm{m}$ nylon net Steriflip Filter Unit (EMD Millipore, Billerica, MA) to remove large seed particles. Filtrates from seed from a single fruit were pooled to produce a ' $\mathrm{Ca}$. L. asiaticus' inoculum.

Culture media. Four different types of liquid culture media were tested. Medium K (24) served as the control medium. Medium J50 was created from equal parts K and "juice" from the ' $C a$. L. asiaticus'-infected fruit used as a source of seed for inoculum (see above). The juice was created as follows: after seed removal, pulp was removed from the infected fruit and thoroughly macerated with $150 \mathrm{ml}$ of deionized water, and the resulting solution was filter sterilized using a $0.22-\mu \mathrm{m}$ filter. In three initial experiments (see below), variations of J50 called J20, J24, and J25 (containing 20, 24, and 25\% juice, respectively) were used. Medium G50 was created from equal parts K and filter-sterilized commercially available grapefruit juice (Simply Grapefruit; Simply Orange Juice Company, Apopka, FL). Medium G contained 100\% commercially available grapefruit juice. Filter-sterilized grapefruit juice was prepared fresh for each experiment from different bottles of juice $(\approx 1$ bottle per three experiments) purchased at different times during the course of this research. Before each experiment was performed, the $\mathrm{pH}$ and salinity of the media were measured using $\mathrm{pH}$ strips (pH 2.0 to 9.0) and a Vital Sine SR-6 salinity refractometer (Pentair AES, Apopka, FL), respectively. Brix was measured using a Mark II Digital Refractometer (Reichert, Depew, NY).

Mineral element characterization. To further characterize chemical differences between culture media, media samples were analyzed by inductively coupled plasma optical emission spectrometry (ICP-OES) using an Optima 7100 DV (Perkin Elmer,
Waltham, MA) with simultaneous measurement of $\mathrm{B}, \mathrm{Ca}, \mathrm{Cu}, \mathrm{Fe}$, $\mathrm{K}, \mathrm{Mg}, \mathrm{Mn}, \mathrm{Na}, \mathrm{Ni}, \mathrm{P}, \mathrm{S}$, and $\mathrm{Zn}$, as previously described (7). Samples were digested for $30 \mathrm{~min}$ at $99^{\circ} \mathrm{C}$ and overnight at room temperature (to completion) in $200 \mu \mathrm{l}$ of Optima metal-free concentrated nitric acid (Fisher Scientific, Pittsburgh). After dilution with ultrapure, metal-free water and centrifugation at 13,000 $\times g$ to remove any remaining particulates, samples were analyzed. Metal concentrations were determined by comparing emission intensities with a standard curve created from certified metal standards (SPEX CertiPrep, Metuchen, NJ). Standard curves were confirmed by reanalysis of standard solutions diluted in a matrix equivalent to the sample. Individual readings are the average of two intensity measurements variable by $<5 \%$.

Organic components characterization. Sugars, amino acids, and organic acids in media were characterized by gas chromatography-mass spectrometry (GC-MS). For the sugar derivatization, samples were diluted 1:5 in distilled water, and $5 \mu \mathrm{l}$ was transferred to a 2-ml microreaction vessel and dried under a nitrogen stream. The dried sample was mixed with $30 \mu \mathrm{l}$ of MOX Reagent (Thermo Fisher Scientific, Waltham, MA) and allowed to react for $17 \mathrm{~h}$ at room temperature (18). Finally, the sample was mixed with $80 \mu \mathrm{l}$ of $\mathrm{N}$-methyl-(N-trimethylsilyl) trifluoracetamide for $2 \mathrm{~h}$ at room temperature, and $0.3 \mu \mathrm{l}$ of derivatized sample was injected into the GC-MS running in full-scan mode. Sucrose, glucose, and fructose standards $(5,2.5,1.25$, and $0.62 \mu 1$ at $10,000 \mathrm{ppm}$ ) (Fisher Scientific) were dried and derivatized as described above for quantification of unknowns. For amino acids, $40 \mu \mathrm{l}$ of amino acid standards or media samples were transferred to a 1-ml GC-MS silanized insert, derivatized with methylchloroformate (MCF), and analyzed as described $(46,55)$. Arginine cannot be detected by the MCF method (6).

Derivatized samples were analyzed using a Clarus 500 GC-MS system (Perkin Elmer) fitted with an HP-5ms column $(0.22 \mathrm{~mm}$ i.d. by $50 \mathrm{~m}$ in length by $0.025-\mu \mathrm{m}$ film thickness) (Agilent Technologies, Santa Clara, CA). The helium carrier gas flow rate was $0.7 \mathrm{ml} / \mathrm{min}$. A modified temperature program was used (55): $70^{\circ} \mathrm{C}$ for $5 \mathrm{~min}$, increase to $180^{\circ} \mathrm{C}$ at a rate of $10^{\circ} \mathrm{C} / \mathrm{min}$, hold for $2 \mathrm{~min}$, increase to $280^{\circ} \mathrm{C}$ at $10^{\circ} \mathrm{C} / \mathrm{min}$, hold for $1 \mathrm{~min}$, increase to $300^{\circ} \mathrm{C}$ at $10^{\circ} \mathrm{C} / \mathrm{min}$, and hold for $5 \mathrm{~min}$. The injector and detector temperatures were 250 and $180^{\circ} \mathrm{C}$, respectively.

GC-MS chromatograms were analyzed and normalized using internal standards in TurboMass software (version 5.4.2; Perkin Elmer). Peaks were identified using the Wiley Registry 9th Edition/NIST 2011 Mass Spectral Library (National Institute of Standards and Technology, Gaithersburg, MD; John Wiley and Sons, Hoboken, NJ). Identification was confirmed by comparing sample retention time and mass spectra with available standards.

Time-series experiments. Experiments were conducted to test the viability of ' $C a$. L. asiaticus' in each of the different culture media over time. For each time-series, an experiment was defined as the group of cultures started with ' $\mathrm{Ca}$. L. asiaticus' inoculum derived from only one pomelo fruit, with two separate experiments (from two separate pomelo fruit) often being initiated on the same day. For each media treatment, $50 \mathrm{ml}$ of media was added to two independent replicate 250-ml sterile glass Erlenmeyer flasks. Immediately after inoculum preparation, each flask was inoculated with $5 \mathrm{ml}$ of ' $\mathrm{Ca}$. L. asiaticus' inoculum. The contents were mixed, and flasks were stoppered with sterile foam plugs covered with foil and stored in the dark at room temperature. Starting immediately after inoculation, samples (pseudoreplicates) were collected from each flask every other day, treated, and stored as described below. Five initial time-series experiments with variable experimental designs were conducted from April to October 2011 (Table 1, experiments 1 to 5). Subsequently, eight identical time-series experiments were conducted in November 2011 (Table 1, experiments 6 to 13), followed by four similar experiments in 2012 (Table 1, experiments 14 to 17). 
At each time point, six 200- $\mu$ l pseudoreplicate samples from each flask were aliquotted into 1.7-ml microtubes. Half of these samples from each flask $(n=3)$ were treated with EMA according to previously described methods for ' $\mathrm{Ca}$. L. asiaticus' (51) that were based on previously optimized and validated methods $(35,36)$. Briefly, EMA $(5 \mathrm{mg} / \mathrm{ml})$ was added to each sample to achieve a final concentration for EMA of $100 \mu \mathrm{g} / \mathrm{ml}$, and samples were incubated in the dark for $5 \mathrm{~min}$ with occasional inversion. Then, EMA-treated sample tubes were opened, placed on ice, and exposed to a 700-W halogen lamp at a distance of $20 \mathrm{~cm}$ for 2 min. All samples, both EMA-treated and nontreated, were then stored at $-80^{\circ} \mathrm{C}$ until being used for molecular analyses.

During the time series, flasks were monitored for visual evidence of co-cultured (non- ' $\mathrm{Ca}$. L. asiaticus') bacterial growth, presumed to be any rapidly growing bacteria. For experiments 6 to 13, cultures were also monitored for growth of bacterial colonies ('Ca. L. asiaticus' or co-cultured bacteria) on solid media. Culture samples $(100 \mu \mathrm{l})$ from each flask were spread plated on K and G50 media agar plates at the initial and fourth time points for experiments 6 to 9 and at the initial time point only for experiments 10 to 13 . All plates were incubated under the same conditions as the flasks and checked regularly for growth.

Biofilm analyses. During time-series experiments, it was noted that a biofilm-like substance reproducibly formed at the air-liquid interface of the flasks. At $\approx 2$ months after the time-series experiments were concluded and production of this biofilm-like substance (henceforth referred to as "biofilm") had stopped, analyses were performed to compare the amount of biofilm between treatments. The thickness of the biofilm ring formed in each flask was semiquantitatively assessed for experiments 6 to 13 and 16 to 17 using the following scale: $0=$ none, $1=$ trace, $2=$ medium, and $3=$ thick. To determine whether ' $\mathrm{Ca}$. L. asiaticus' was present in this biofilm, the biofilm was collected from each flask from experiments 6, 16, and 17 for analysis. First, all media containing planktonic cells were removed and saved. The flask was rinsed twice with $1 \mathrm{ml}$ of water, carefully, so as not to disturb the biofilm, and $2 \mathrm{ml}$ of $\mathrm{K}$ medium was added. The biofilm was scraped off and resuspended in the media. Samples of the biofilm suspension and the media with planktonic cells, both EMAtreated and untreated as previously described, were saved for subsequent molecular analyses.

To determine whether the biofilm-like substance was biofilm, the presence of intact bacterial cells surrounded by an exopolysaccharide (EPS) matrix was assessed. Replicate 50-ml conicals containing $10 \mathrm{ml}$ of $\mathrm{K}$ or $\mathrm{G}$ medium were inoculated with $1 \mathrm{ml}$ of seed inoculum (same inoculum as experiment 16). Glass slides were inserted into each conical and cultures were incubated for $\approx 2$ months, during which time biofilm formed on them. Slides were removed and dipped twice in $1 \times$ phosphate-buffered saline (PBS). The LIVE/DEAD BacLight Bacterial Viability and Counting Kit (Life Technologies Corporation, Grand Island, NY) was used to stain the biofilm according to the manufacturer's directions. Slides were again dipped in PBS. A solution of calcofluor white at $10 \mathrm{mg} / \mathrm{ml}$ was applied to cover the biofilm and allowed to stain it for $15 \mathrm{~min}$ in the dark, and slides were dipped again in PBS. Micrographs were taken on a Nikon Eclipse Ti inverted microscope (Nikon, Melville, NY) at $\times 40$ fluorescent optics using NIS-Elements imaging software (Ver. 3.0; Nikon).

qPCR analyses. EMA-treated and nontreated samples were processed with a modified cetyltrimethylammonium bromide DNA extraction procedure (11), and DNA pellets were resuspended in $25 \mu \mathrm{l}$ of molecular-grade water. qPCR using the previously described HLBas/HLBr/HLBp primer and TaqMan probe set (26) was then used to quantify ' $\mathrm{Ca}$. L. asiaticus' DNA in each sample. A duplicate four-point standard curve consisting of 10-fold serial dilutions of the plasmid pLas16S (described below) was amplified alongside the samples in each qPCR for quantification of the unknowns. Aliquots of standards were used twice and then disposed of to avoid degradation. DNA was amplified on an Applied Biosystems 7500 Real-Time PCR System (Life Technologies Corporation) in reactions $(20 \mu \mathrm{l})$ containing the following components: 1× ABsolute Blue QPCR ROX Mix (ABgene UK, Epsom, Surrey), $0.25 \mu \mathrm{M}$ each primer, $0.15 \mu \mathrm{M}$ probe (labeled 5'6 FAM, 3'-BHQ1), and $1 \mu \mathrm{l}$ of DNA template. Cycling parameters were $95^{\circ} \mathrm{C}$ for $15 \mathrm{~min}$, followed by 45 cycles of $95^{\circ} \mathrm{C}$ for $15 \mathrm{~s}$ and $58^{\circ} \mathrm{C}$ for $1 \mathrm{~min}$. Samples were diluted $1 / 10$ and reanalyzed as needed to overcome reaction inhibition. Reaction efficiencies of 90 to $110 \%$ were confirmed for each qPCR run.

Plasmid standard for ' $\boldsymbol{C a}$. L. asiaticus' quantification. The primer HLBas used in TaqMan qPCR detection of ' $\mathrm{Ca}$. L. asiaticus' (26) is missing a G between base 14 and 15 (6 bp from the $3^{\prime}$ end) that is present in the target genomic sequence (Supplemental Figure 1). This base is also missing from the OI1 primer used for amplifying $16 \mathrm{~S}$ sequences (23) and from plasmid standards used for ' $C a$. L. asiaticus' quantification (27). This error in primer sequences leads to a perfect match to plasmid standards but a sequence mismatch to target ' $C a$. L. asiaticus' DNA. To determine whether this mismatch affected ' $\mathrm{Ca}$. L. asiaticus' quantification using HLBas, a plasmid standard (pLas16S) was constructed with the corrected ' $\mathrm{Ca}$. L. asiaticus' $16 \mathrm{~S}$ rDNA sequence by amplifying the target fragment and surrounding sequences. The sequence was amplified with the nonspecific forward primer EJ044 5'-GGAGACGTGGACGGCGGTTT-3' and the reverse primer OI2c (23). The amplicon was gel purified using the QIAquick Gel Extraction Kit (Qiagen, Valencia, CA) and cloned into the pDrive cloning vector using the Qiagen PCR Cloning Kit

TABLE 1. Time series experiments conducted from 2011 to $2012^{\mathrm{v}}$

\begin{tabular}{|c|c|c|c|c|c|c|}
\hline Experiment IDs & Date $^{\mathrm{w}}$ & $N^{\mathrm{x}}$ & Pomelo variety & Treatments $^{\mathrm{y}}$ & Time points & Duration (days) \\
\hline 1 & 18 April 2011 & 1 & Mato Buntan & $\mathrm{K}, \mathrm{J} 24$ & 5 & 25 \\
\hline 2 & 22 June 2011 & 1 & Mato Buntan & $\mathrm{K}, \mathrm{J} 25, \mathrm{~J} 50$ & 6 & 14 \\
\hline 3 & 10 August 2011 & 1 & Mato Buntan & K, J20, J50 & 4 & 7 \\
\hline $4^{z}$ & 9 September 2011 & 1 & Mato Buntan & K, J50, G50 & 7 & 13 \\
\hline $5^{z}$ & 12 October 2011 & 1 & Mato Buntan & K, J50, G50 & 10 & 18 \\
\hline $6^{\mathrm{z}}, 7$ & 9 November 2011 & 2 & Mato Buntan & $\mathrm{K}, \mathrm{J} 50, \mathrm{G} 50, \mathrm{G}$ & 10 & 18 \\
\hline 8,9 & 17 November 2011 & 2 & Mato Buntan & $\mathrm{K}, \mathrm{J} 50, \mathrm{G} 50, \mathrm{G}$ & 10 & 18 \\
\hline $10,11^{\mathrm{z}}$ & 22 November 2011 & 2 & Mato Buntan & $\mathrm{K}, \mathrm{J} 50, \mathrm{G} 50, \mathrm{G}$ & 10 & 18 \\
\hline 12,13 & 30 November 2011 & 2 & Mato Buntan & $\mathrm{K}, \mathrm{J} 50, \mathrm{G} 50, \mathrm{G}$ & 10 & 18 \\
\hline 14,15 & 28 February 2012 & 2 & Mato Buntan & $\mathrm{K}, \mathrm{G} 50, \mathrm{G}$ & 3 & 20 \\
\hline 16,17 & 5 September 2012 & 2 & Liane, Mato Buntan & $\mathrm{K}, \mathrm{G}$ & 5 & 30 \\
\hline
\end{tabular}

${ }^{\mathrm{v}}$ Each experiment was conducted with 'Candidatus Liberibacter asiaticus' obtained from a single pomelo fruit, with two replicate flask cultures per medium.

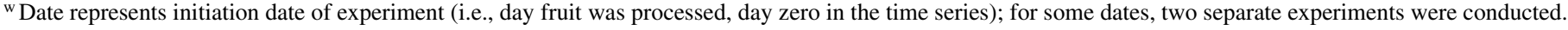

${ }^{x}$ Number of experiments.

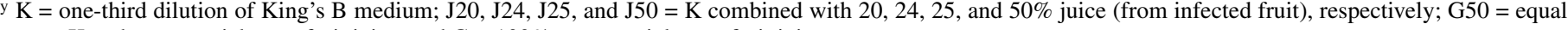
parts $\mathrm{K}$ and commercial grapefruit juice; and $\mathrm{G}=100 \%$ commercial grapefruit juice.

z Detailed quantitative polymerase chain reaction analysis of total and viable ' $\mathrm{Ca}$. L. asiaticus' cells presented in Results. 
and transformed into Escherichia coli DH5 $\alpha$. The construct was confirmed by DNA sequencing. Comparison of standard curves made from pLas 16S and a similar plasmid (pHLBas) containing the primer sequence constructed as above with a PCR product of primers HLBas and OI2c showed that the sequence mismatch led to a 1.8 to $4.2 \log$ underestimation of target sequence concentrations (Supplemental Figure 2). Therefore, pLas16S was used for accurate quantification in the experiments described here.

$16 S$ rDNA next-generation sequencing. Triplicate DNA samples from initial inoculum (I) and post-experiment biofilm $(\mathrm{BF})$ and planktonic $(\mathrm{P})$ fractions from time-series cultures were pooled from experiment 6 , for a total of eight pooled samples: I, K BF, K P, G50 BF (two replicates), G50 P, G BF, and G P. DNA was quantified using a Qubit 2.0 fluorometer and double-stranded DNA HS Assay Kit (Life Technologies Corporation). The V4 region of the $16 \mathrm{~S}$ rDNA gene from samples was PCR-amplified on a MyCycler Thermal Cycler (Bio-Rad Laboratories, Hercules, CA) using the previously published F515/R806 primer set (4), with the reverse primer being individually barcoded for each sample. PCR reactions $(40 \mu \mathrm{l})$ contained $1 \times \mathrm{KAPA}$ HiFi HotStart ReadyMix (Kapa Biosystems, Woburn, MA), $10 \mu \mathrm{M}$ each primer, and 10 to $30 \mathrm{ng}$ of DNA. Cycling parameters were $95^{\circ} \mathrm{C}$ for $2 \mathrm{~min}$; followed by 12 cycles of $98^{\circ} \mathrm{C}$ for $20 \mathrm{~s}, 61^{\circ} \mathrm{C}$ (decreasing $1^{\circ} \mathrm{C} / \mathrm{s}$ ) for $30 \mathrm{~s}$, and $72^{\circ} \mathrm{C}$ for $30 \mathrm{~s}$; followed by 20 cycles of $98^{\circ} \mathrm{C}$ for $20 \mathrm{~s}, 50^{\circ} \mathrm{C}$ for $30 \mathrm{~s}$, and $72^{\circ} \mathrm{C}$ for $30 \mathrm{~s}$; with a final step of $72^{\circ} \mathrm{C}$ for $10 \mathrm{~min}$. Two samples (G50 P and G BF) could not be amplified due to insufficient availability of DNA.

Amplified samples were ethanol precipitated and pellets were resuspended in $15 \mu \mathrm{l}$ of molecular-grade water. Amplification was confirmed by gel electrophoresis, and amplicons from successfully amplified samples were quantified using the Qubit and pooled at equimolar concentrations. The pooled library was size selected using the E.Z.N.A. NGS Clean-IT Kit (Omega Bio-Tek, Norcross, GA) to remove smaller fragments. The pooled library was again quantified using the Qubit, diluted to $6.1 \mathrm{pM}$, and sequenced on an Illumina MiSeq Personal Sequencer (Illumina, San Diego, CA) along with $30 \%$ PhiX control.

Paired read sequences were assembled into contigs using Geneious version 5.4.6 (created by Biomatters; www.geneious. com). Sequences of bacterial origin (the bacterial metagenome) were identified using Geneious to exclude chloroplast, mitochondrial, or phage-derived sequences from further analyses. The Ribosomal Database Project (RDP) Classifier version 2.5 (8) was used to assign taxa to bacterial contig consensus sequences generated in Geneious using a confidence threshold of $60 \%$. The GenBank database in conjunction with the blastn algorithm was also used to confirm operational taxonomic unit (OTU) similarity. Paired read sequences are available at the Sequence Read Archive (accessions SRR786740 and SRR786989-SRR786993). The National Center for Biotechnology Information BioProject accession is PRJNA193341, and the BioSample accessions are SAMN01983988, SAMN01983993, and SAMN01984091 to SAMN01984093.

Data analyses. To assess overall temporal trends in ' $\mathrm{Ca}$. L. asiaticus' cell concentration and viability, the means and standard errors of qPCR data from all initial time point samples from all experiments (Table 1) were calculated. Means and standard errors from all time points were calculated for experiments $4,5,6$, and 11. Outliers were identified as maximum and minimum values which were $>0.5 \log$ larger or smaller, respectively, than the next closest value and were removed prior to these calculations. Means and standard errors were then plotted by experimental start date for experiments 5 and 6 . Samples were compared at each time point between the different media types using Wilcoxon-MannWhitney rank-sum tests implemented in Statistix (v. 8.0; Analytical Software, Tallahassee, FL).

Mean and standard errors were calculated for ICP-OES nutrient concentrations for $\mathrm{K}(n=6)$, J50 $(n=10)$, G50 $(n=6)$, and $\mathrm{G}$ $(n=4)$. Comparisons of nutrient concentrations between different media types were made using one-way analysis of variance (ANOVA) or Kruskal-Wallis for non-normal data and means separated by Fisher's protected least significant difference test $(P<0.05)$ using Statistix 8.0. GC-MS data were statistically analyzed using one-way ANOVA followed by Tukey's test to compare compounds among media $(P<0.05)$.

A Kruskal-Wallis test and a post-hoc test using WilcoxonMann-Whitney rank-sum tests with Bonferroni correction were used to identify significant differences $(P<0.05)$ in biofilm formation between media types. These tests were performed in the R v2.15.3 statistical software environment (The R Foundation for Statistical Computing, 2013, Vienna, Austria).

\section{RESULTS}

' $C a$. L. asiaticus' viability in different media over time. Four experiments which had higher initial concentrations of ' $\mathrm{Ca}$. L. asiaticus' and limited visual evidence of contamination (i.e., not compromised by fast-growing contaminants) were selected for qPCR analyses of total ' $C a$. L. asiaticus' cells and viable (EMAtreated) ' $\mathrm{Ca}$. L. asiaticus' cells: experiments $4,5,6$, and 11 . There is significant between-experiment variability in initial ' $C a$. L. asiaticus' concentration in these liquid cultures, because ' $\mathrm{Ca}$. L. asiaticus' inoculum concentrations reflect the variable ' $C a$. L. asiaticus' concentrations in pomelo seed during the growing season (see below). Mean initial time point ' $\mathrm{Ca}$. L. asiaticus' concentrations in cultures from each experiment, presented as total cells (viable cells) per milliliter if culture, were, chronologically: $7.8 \times 10^{6}\left(9.8 \times 10^{5}\right), 4.6 \times 10^{5}\left(6.8 \times 10^{4}\right), 1.5 \times 10^{5}$ $\left(3.3 \times 10^{4}\right)$, and $2.5 \times 10^{5}\left(3.3 \times 10^{4}\right)$.

However, clear trends are apparent in all four time series, despite variability in initial ' $C a$. L. asiaticus' concentrations. In all four experiments, ' $C a$. L. asiaticus' viability over time is reduced in medium $\mathrm{K}$ compared with all other media (Fig. 1, two example experiments). Although the initial concentration of viable ' $\mathrm{Ca}$. L. asiaticus' cells is generally the same across all types of media (as expected), the concentration of viable cells in medium $\mathrm{K}$ decreases over time, generally reaching and staying at a level of effectively zero viable cells at $\approx 4$ to 12 days after inoculation. Mean final time point ' $\mathrm{Ca}$. L. asiaticus' concentrations in medium $\mathrm{K}$ from each experiment, presented as total cells (viable cells) per milliliter of culture, were, chronologically $1.7 \times 10^{5}\left(6.6 \times 10^{2}\right), 0$ (0), $2.5 \times 10^{4}(5.4)$, and $0(0)$. In media supplemented with citrus juice, however, higher levels of ' $\mathrm{Ca}$. L. asiaticus' cell viability are maintained through the end of the experiment (usually 18 days) (Fig. 1). Mean final time point ' $\mathrm{Ca}$. L. asiaticus' concentrations in juice-containing flasks from each experiment, presented as total cells (viable cells) per milliliter of culture, were, chronologically $1.3 \times 10^{6}\left(6.7 \times 10^{5}\right), 1.0 \times 10^{6}\left(4.1 \times 10^{5}\right), 5.4 \times 10^{4}\left(2.5 \times 10^{4}\right)$, and $2.7 \times 10^{4}\left(8.1 \times 10^{3}\right)$.

For the two experiments for which qPCR of the complete time series was conducted (Fig. 1), average percent viability throughout the course of the experiment (excluding the initial time point, day zero) was determined. For experiment 5, average ' $C a$. L. asiaticus' percent viability in $\mathrm{K}$ was $4 \%$ (range 0 to $12 \%$ ) whereas, in juice-containing media, it was $36 \%$ (range 10 to $64 \%$ ). For experiment 6 , average ' $\mathrm{Ca}$. L. asiaticus' percent viability in $\mathrm{K}$ was $2 \%$ (range 0 to $7 \%$ ) and in juice-containing media it was $37 \%$ (range 12 to $68 \%$ ). Over the course of these time series, the maximum ratios of ' $\mathrm{Ca}$. L. asiaticus' to initial ' $\mathrm{Ca}$. L. asiaticus' were 7.6 (total) and 15.0 (viable) in experiment 5 and 5.7 (total) and 5.6 (viable) in experiment 6.

All four experiments also show a particular cyclical oscillating pattern in ' $C a$. L. asiaticus' concentrations over time that can occasionally be weakly observed in $\mathrm{K}$ media cultures before all cell viability is lost but is pronounced in all juice-containing cultures throughout the time series (Fig. 1). This pattern is evident 
in both total ' $\mathrm{Ca}$. L. asiaticus' cells and viable ' $\mathrm{Ca}$. L. asiaticus' cells. Furthermore, the oscillation peaks tend to occur at similar points in the time series for all of the different culture treatments.

Annual trends in ' $\mathrm{Ca}$. L. asiaticus' concentration and viability. Initial ' $C a$. L. asiaticus' culture concentrations of all experiments (Fig. 2) were variable through the year but showed an overall annual trend, which reflects the concentration of ' $\mathrm{Ca}$. L. asiaticus' present in the pomelo seed (culture inoculum source). Total as well as viable ' $C a$. L. asiaticus' cell concentrations increased as the year's fruit crop ripened, peaking around September (Fig. 2). After this point, total and viable ' $\mathrm{Ca}$. L. asiaticus' cell concentrations decreased for the rest of the crop season. The percentage of viable ' $\mathrm{Ca}$. L. asiaticus' cells is somewhat variable but is generally $\approx 16 \%$ (range 4 to $34 \%$ ) (Fig. 2).

Media characterization. Media characterization via measurements of $\mathrm{pH}$, salinity, Brix, mineral element, and organic compound concentrations showed that the composition of each medium was consistent between experiments (Figs. 3 and 4; Tables 2 and 3 ). However, there were distinct differences in composition between media types. $\mathrm{pH}$ was the highest in medium $\mathrm{K}$ and the lowest in medium $\mathrm{G}$, while salinity and Brix were the lowest in $\mathrm{K}$ and the highest in $\mathrm{G}$ (Fig. 3).

Mineral element concentrations of most elements analyzed $(\mathrm{Ca}$, $\mathrm{K}, \mathrm{Mg}, \mathrm{B}, \mathrm{Cu}, \mathrm{Fe}, \mathrm{Mn}, \mathrm{Ni}$, and $\mathrm{Zn}$ ) in media that support ' $\mathrm{Ca}$. $\mathrm{L}$. asiaticus' viability (e.g., G) were significantly $(P<0.05)$ higher than in $\mathrm{K}$, a medium nonconducive for ' $\mathrm{Ca}$. L. asiaticus' viability. The exceptions were $\mathrm{Na}$ and $\mathrm{S}$, which were more abundant in $\mathrm{K}$ than G. Comparison of juices from ' $C a$. L. asiaticus'-infected pomelo (J50) and presumably healthy commercially available grapefruit (G50) indicates that ' $\mathrm{Ca}$. L. asiaticus'-infected fruit had significantly $(P<0.05)$ lower concentrations of $\mathrm{Mg}, \mathrm{P}$, and $\mathrm{S}$, whereas the other elements were nonsignificantly different $(P>$ 0.05). Differences were also found in the organic compounds analyzed. Medium G had significantly $(P<0.05)$ higher concentrations of alanine, serine, and, particularly proline and aspartic acid, which were both 20 -fold higher in $\mathrm{G}$ than $\mathrm{K}$ (Table 2). $\mathrm{K}$ had roughly twofold $(P<0.05)$ more isoleucine compared with G. Compounds such as succinic acid, $\gamma$-aminobutyric acid, malic
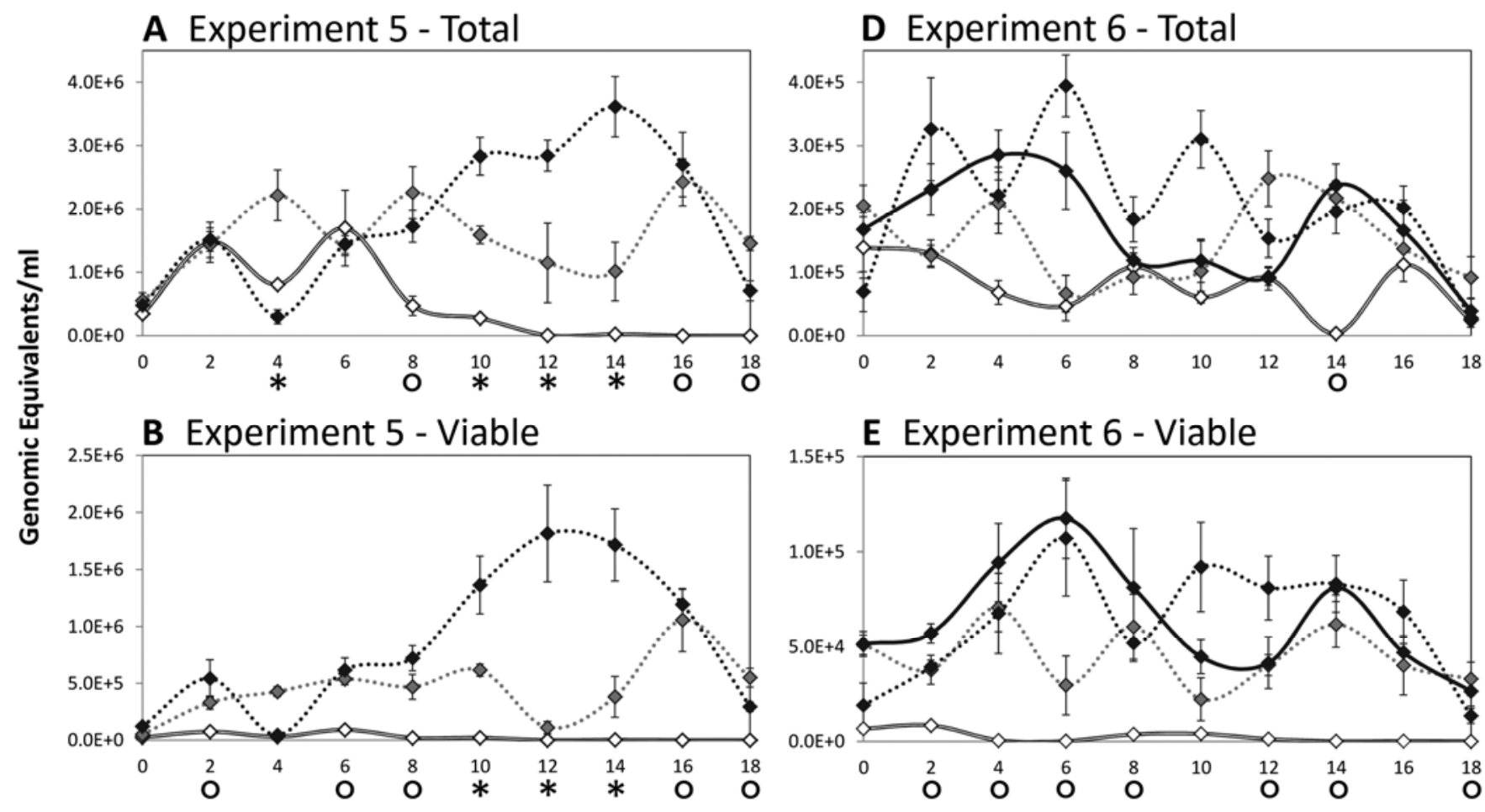

C Experiment 5 - Percent Viable
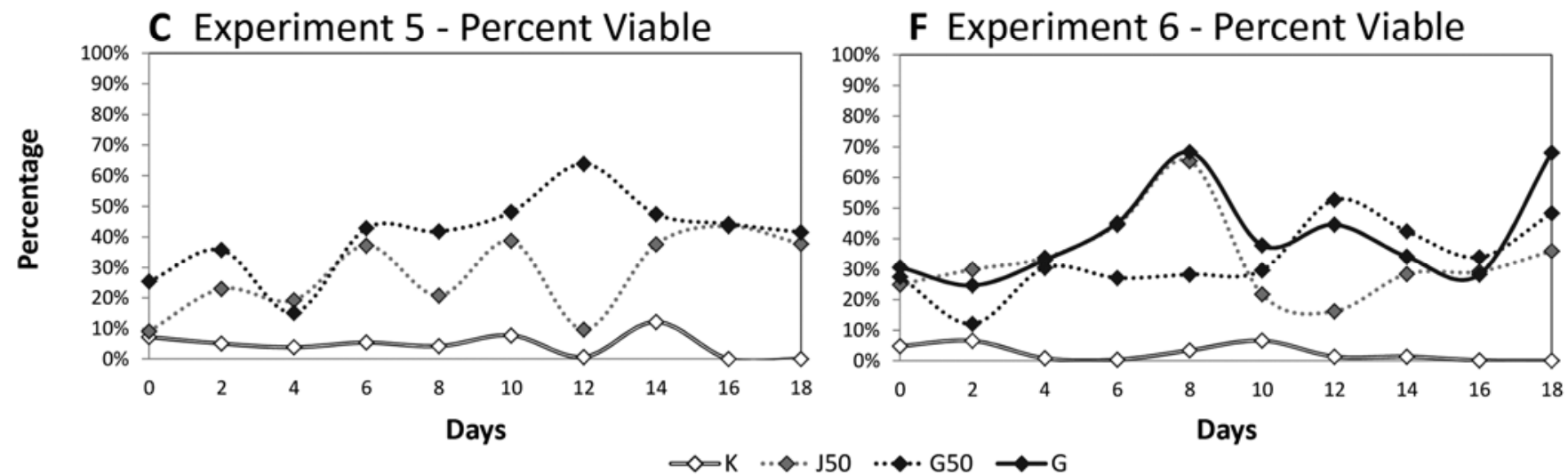

Fig. 1. 'Candidatus Liberibacter asiaticus' concentrations over time from two example time series from independent experiments (four analyzed in total, see Results). A, Experiment 5 total ' $C a$. L. asiaticus'; B, experiment 5 viable ' $\mathrm{Ca}$. L. asiaticus'; C, experiment 5 percent viable ' $\mathrm{Ca}$. L. asiaticus'; D, experiment 6 total 'Ca. L. asiaticus'; E, experiment 6 viable ' $C a$. L. asiaticus'; F, experiment 6 percent viable ' $C a$. L. asiaticus'. Values are mean genomic equivalents per milliliter of culture $( \pm$ standard error) $(\mathrm{A}, \mathrm{B}, \mathrm{D}$, and $\mathrm{E})$ or percentage (viable/total $\times 100)(\mathrm{C}$ and $\mathrm{F})$. Symbols at the bottom of graphs $\mathrm{A}, \mathrm{B}, \mathrm{D}$, and $\mathrm{E}$ indicate significant differences according to Wilcoxon-Mann-Whitney rank-sum tests $(P<0.05)$ between ' $\mathrm{Ca}$. L. asiaticus' populations in different media at specific time points: $*=$ all media differ from each other and $\bigcirc=\mathrm{K}$ medium differ from all juice-containing media (J50, G50, and G). 
acid, citric acid, quinic acid, fructose, glucose, inositol, and sucrose were nondetectable in $\mathrm{K}$ but were present in all juice-containing media. Medium J50 had significantly $(P<0.05)$ lower concentrations of proline and citric acid compared with G50.

Biofilm characterization. Assessments of the amount of biofilm visible at the air-liquid interface of culture flasks from experiments 6 to 13,16, and 17 indicated that the amount of biofilm was greater in all media containing juice (J50, G50, and G) compared with medium K (Fig. 5). A significant effect of media type on biofilm amount $(P<0.001)$ was found. Post-hoc tests showed that significant differences occurred between $\mathrm{K}$ and all the juice-containing media (J50, G50, and G) $(P<0.001)$. Fluorescent images of the biofilms formed on glass slides during experiment 16 (Fig. 6) also showed characteristic differences between biofilms formed in different media. In media $\mathrm{K}$, after $\approx 2$ months of incubation, the majority of the biofilm was composed of dead cells whereas, in media G, the majority of biofilm was composed of live bacterial cells (Fig. 6). An EPS matrix was clearly evident surrounding cells in both biofilms (Fig. 6).

Quantification of ' $\mathrm{Ca}$. L. asiaticus' in biofilm and planktonic fractions. qPCR analysis of biofilm samples collected after the end of time-series experiments 6, 16, and 17 indicated that ' $C a$. L. asiaticus' was rarely detected in biofilm from $\mathrm{K}$ medium, whereas it was always detected, and in higher concentrations, in biofilm from juice-containing media (Fig. 7). Furthermore, viable ' $C a$. L. asiaticus' were only detected in biofilm from juice-containing media (Fig. 7). For comparison, planktonic samples collected at the same time were analyzed. Results indicate that,

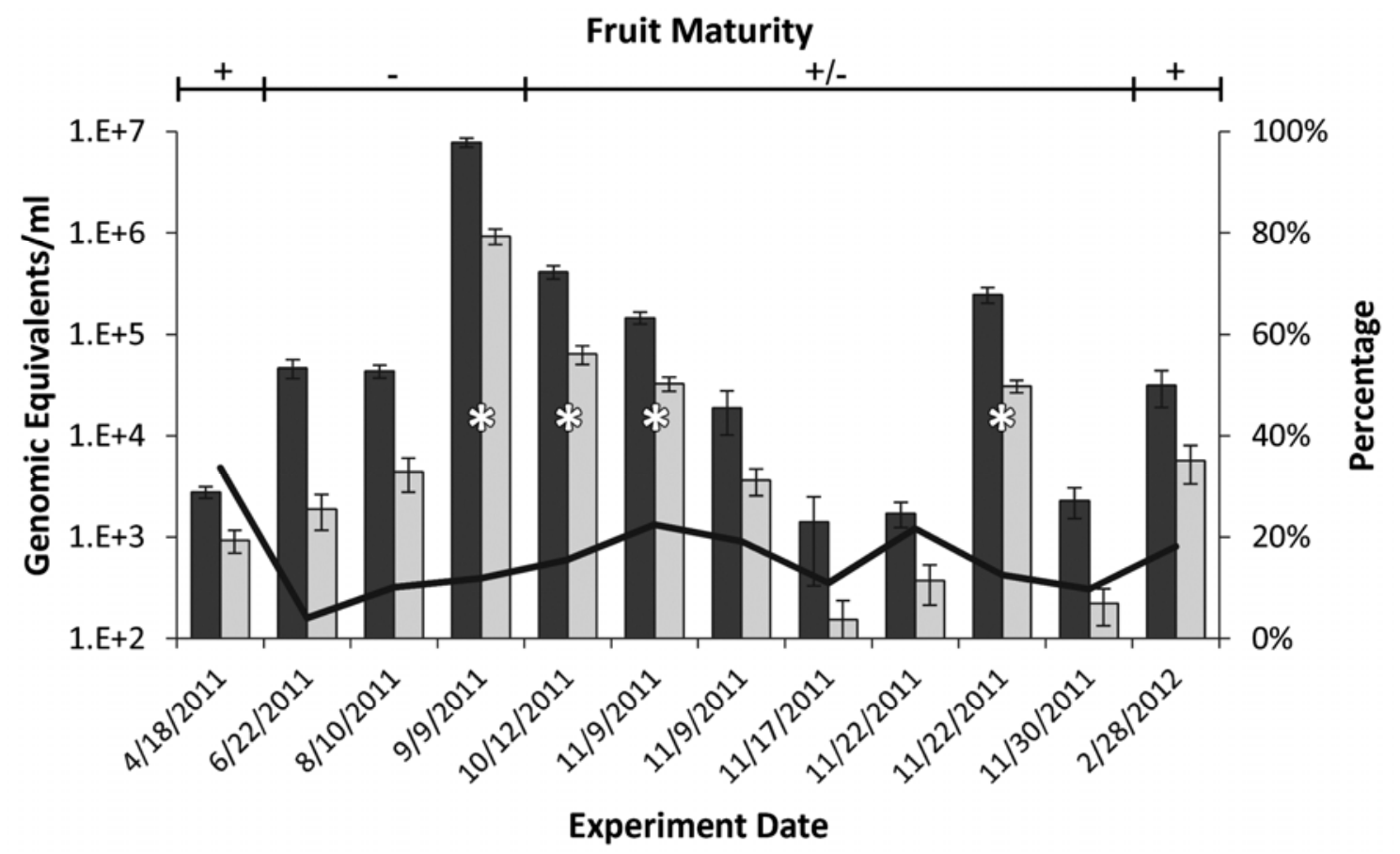

$\square$ Total

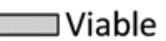

\section{- Percent Viable}

Fig. 2. Initial 'Candidatus Liberibacter asiaticus' concentrations in cultures from all experiments. Values shown are average genomic equivalents per milliliter of culture ( $n=12-36$ quantitative polymerase chain reactions (qPCRs) from assorted samples from culture flasks). The 04/18/11 sample was a mature fruit from the 2010-11 crop, while all other samples are from the 2011-12 crop, beginning with the most immature fruit on 6/22/11. An asterisk (*) denotes experiments for which complete qPCR analysis of time series was conducted. Fruit maturity is indicated on top of the graph: + denotes ripe (yellow) fruit, - denotes unripe (green) fruit, and \pm denotes intermediately ripe (yellow-green) fruit.
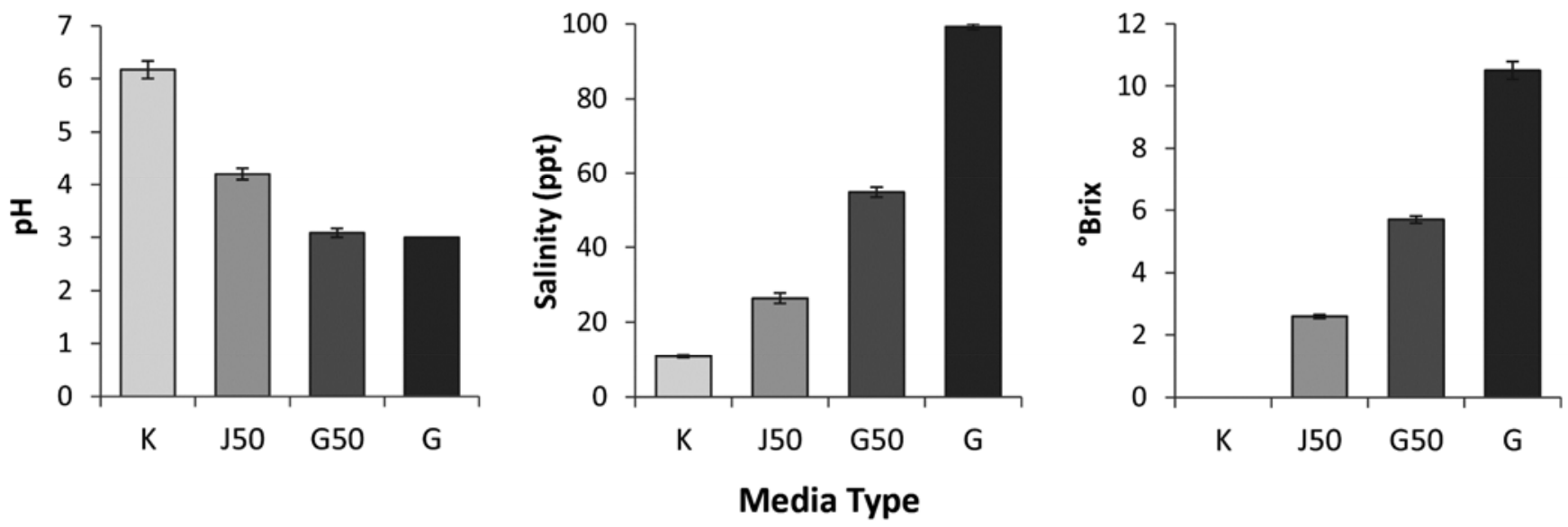

Fig. 3. $\mathrm{pH}$, salinity, and Brix for the different media types. Values are mean \pm standard error from September to November 2011 experiments (experiments 4 to 13 ) $\left(n_{\mathrm{pH} / \text { salinity }}=10\right.$ and $\left.n_{\text {Brix }}=3\right)$. 
though some ' $\mathrm{Ca}$. L. asiaticus', including viable ' $\mathrm{Ca}$. L. asiaticus', were present in $\mathrm{K}$ planktonic samples, concentrations were always at least $1 \log$ lower than in the corresponding $\mathrm{G}$ planktonic sample from the same experiment.

Bacterial populations in inocula and cultures. Visual evidence of co-culture in culture flasks (i.e., rapid overgrowth) was limited. Typically, a slight increase in turbidity occurred in the flasks over the course of the time-series experiments. Varying degrees of bacterial growth were seen on the K agar spread plates from the November 2011 experiments (experiments 6 to 13), ranging from no colonies to hundreds of colonies or confluent growth. No bacterial growth was evident on G50 agar plates.
For further characterization of bacterial populations present in initial inocula and cultures, next-generation sequencing was used. Amplification of the V4 region of the $16 \mathrm{~S}$ rDNA gene was obtained from six experiment 6 samples: I, K BF, K P, G50 BF (two replicates), and G P. Paired assemblies of $16 \mathrm{~S}$ rDNA V4 region reads from bacteria (sequences of chloroplast, mitochondria, and phage origin excluded) were then used to determine relative abundance of the six predominant bacterial genera within each amplified sample, with the remaining bacterial reads assigned to the category "other bacteria".

From the sequenced seed inoculum I, 526 bacterial reads were assembled into 39 contigs. The total number of bacterial reads
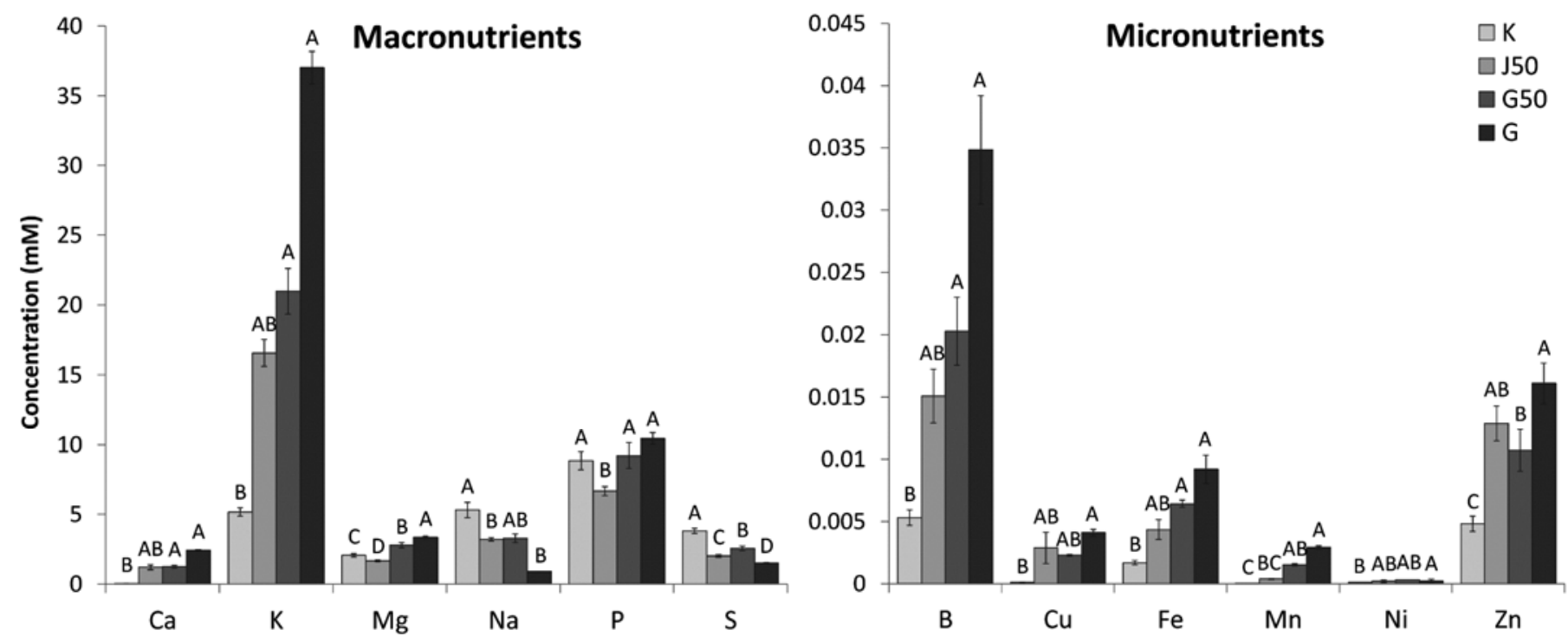

Fig. 4. Nutrient concentrations in culture media as determined by inductively coupled plasma optical emission spectrometry. Values are mean ( \pm standard error) from September to November 2011 experiments (experiments 4 to 13$)$ for each medium: K $(n=6)$, J50 $(n=10)$, G50 $(n=6)$, and G $(n=4)$. Different letters above bars indicate statistically significant differences between the different media based on one-way analysis of variance or Kruskal-Wallis for non-normal data and means separated by Fisher's protected least significant difference test $(P \leq 0.05)$.

TABLE 2. Amino acids and organic acids detected in different media utilized in this study

\begin{tabular}{|c|c|c|c|c|c|c|}
\hline \multirow[b]{2}{*}{ Compound $^{\mathrm{w}}$} & \multirow[b]{2}{*}{$\mathrm{RT}^{\mathrm{x}}$} & \multirow[b]{2}{*}{ Detected fragment $(\mathrm{m} / \mathrm{z})^{\mathrm{y}}$} & \multicolumn{4}{|c|}{ Concentration in each media $(\mathrm{mM})^{\mathrm{z}}$} \\
\hline & & & $\mathrm{K}$ & $\mathrm{J} 50$ & G50 & G \\
\hline Alanine & 12.4 & 102 & $0.46 \pm 0.27 \mathrm{~b}$ & $1.26 \pm 0.36 \mathrm{a}$ & $1.01 \pm 0.1 \mathrm{ab}$ & $1.55 \pm 0.30 \mathrm{a}$ \\
\hline Aspartic acid & 17.64 & 160 & $0.16 \pm 0.06 \mathrm{c}$ & $1.20 \pm 0.28 b c$ & $1.93 \pm 0.25 b$ & $3.88 \pm 0.84 \mathrm{a}$ \\
\hline Cysteine & 21.55 & 192 & ND & ND & ND & ND \\
\hline Glutamic acid & 19.69 & 174 & $0.07 \pm 0.05$ & $0.11 \pm 0.09$ & $0.14 \pm 0.03$ & $0.16 \pm 0.00$ \\
\hline Glycine & 12.37 & 88 & $0.30 \pm 0.17$ & $0.38 \pm 0.09$ & $0.30 \pm 0.05$ & $0.24 \pm 0.04$ \\
\hline Malic acid & 16.32 & TIC & ND & $0.89 \pm 0.20$ & $0.65 \pm 0.00$ & $1.04 \pm 0.45$ \\
\hline Methionine & 20.12 & 147 & $0.10 \pm 0.07$ & $0.09 \pm 0.04$ & $0.06 \pm 0.00$ & $0.01 \pm 0.00$ \\
\hline Phenylalanine & 22.07 & 162 & $0.26 \pm 0.15$ & $0.24 \pm 0.06$ & $0.25 \pm 0.02$ & $0.14 \pm 0.04$ \\
\hline Proline & 16.71 & 128 & $0.28 \pm 0.10 c$ & $1.07 \pm 0.13 \mathrm{c}$ & $3.27 \pm 0.41 \mathrm{~b}$ & $5.79 \pm 0.80 \mathrm{a}$ \\
\hline Serine & 18.73 & 100 & $0.01 \pm 0.01 \mathrm{~b}$ & $0.04 \pm 0.02 \mathrm{ab}$ & $0.04 \pm 0.01 \mathrm{ab}$ & $0.07 \pm 0.02 \mathrm{a}$ \\
\hline Succinic acid & 10.78 & 115 & ND & $0.01 \pm 0.00 \mathrm{~b}$ & $0.03 \pm 0.0 \mathrm{~b}$ & $0.06 \pm 0.01 \mathrm{a}$ \\
\hline
\end{tabular}

${ }^{\mathrm{w}}$ Compounds were detected by gas chromatography-mass spectrometry (GC-MS) after methylchloroformate derivatization (see Materials and Methods for more details).

${ }^{\mathrm{x}}$ Retention time.

y Because malic and citric acids showed large peaks by GC-MS, they were quantified using total ion chromatography (TIC).

${ }^{z}$ Values represent mean and standard deviation $(n=3)$ of concentrations of each compound in the four different media used in this study. $\mathrm{K}=$ one-third dilution of King's B medium; J20, J24, J25, and J50 = K combined with 20, 24, 25, and 50\% juice (from infected fruit), respectively; G50 = equal parts K and commercial grapefruit juice; and $\mathrm{G}=100 \%$ commercial grapefruit juice. Different letters in the same row indicate significant difference $(P<0.05)$ according to one-way analysis of variance and Tukey's test. $\mathrm{ND}=$ nondetectable, or below detection limit. 
from the inoculum was low due to the high percentages of contaminating chloroplast $(68 \%)$ and mitochondrial $(29 \%)$ reads. ' $\mathrm{Ca}$. L. asiaticus' was the primary bacterial component of the seed inoculum at $54 \%$ of bacterial reads. The other predominant bacteria in the sample were, in order of prevalence, species of Flavobacterium (6\%), Pedobacter (6\%), Nevskia (4\%), Bacillus (4\%), and Sediminibacterium (3\%).

Three samples from juice-containing media were sequenced: two replicate biofilm samples $(\mathrm{G} 50 \mathrm{BF})$ and one planktonic sample (G P). Biofilm samples from replicate G50 flasks had 8,046 and 7,651 bacterial reads, which assembled into 34 and 44 contigs, respectively. The predominant bacterial genera present in these replicate samples were species of Pseudomonas (35/34\%), Sediminibacterium (18/18\%), Phenylobacterium (16/17\%), Flavobacterium (13/15\%), Burkholderia (6/2\%), and Pedobacter $(5 / 6 \%)$. The planktonic sample from a $\mathrm{G}$ flask had 5,080 bacterial reads, which were assembled into 114 contigs. The same bacterial genera were predominant, as in the biofilm samples, though with different relative abundances (data not shown).

Two samples from $\mathrm{K}$ medium (non-juice-containing control) were sequenced: one biofilm sample (K BF) and one planktonic sample (K P). K BF had 136,630 bacterial reads which were assembled into 23 contigs. K P had 81,376 bacterial reads which assembled into 121 contigs. Both of these samples were composed predominantly of Bacillus spp. (data not shown). Bacterial reads classified as Bacillaceae at an RDP bootstrap cutoff of $50 \%$ had a relative abundance of $99.9 \%$ in $\mathrm{K} \mathrm{BF}$ and $99.7 \%$ in $\mathrm{K} \mathrm{P}$.

\section{DISCUSSION}

Viability of ' $\boldsymbol{C a}$. L. asiaticus' over time. In the present study, culture conditions were defined that reproducibly prolong viability of ' $C a$. L. asiaticus' in vitro. In particular, addition of commercially available grapefruit juice to the culture medium allows ' $\mathrm{Ca}$. L. asiaticus' viability to be maintained for at least several weeks without passaging the cultures. Previous attempts to establish an in vitro culture of ' $\mathrm{Ca}$. L. spp.' have yielded evidence of growth $(9,42)$, though the culture media were not standardized and the cultures not reproducible. The present study was designed to understand the growth needs of ' $\mathrm{Ca}$. L. asiaticus' by systematically quantifying the viability of ' $\mathrm{Ca}$. L. asiaticus' over time in different types of media.

Selection of media types and culture conditions for ' $\mathrm{Ca}$. L. asiaticus' culture was guided by recommendations for culturing "unculturable" bacteria $(47,54)$. The two main strategies responsible for much of the recent progress in culturing previously unculturable bacteria have been identified as (i) reproducing the bacterium's natural environment as closely as possible $(47,54)$ and (ii) employing co-culture with bacteria from the same environment to supply missing environmental signals or nutritional conditions (47). The experimental design attempted to implement both of these culture strategies.

Media were selected based on research that suggests that ' $C a$. L. asiaticus' may prefer a low-nutrient medium supplemented with an environmental extract (42). King's B, a low-iron medium, was selected for its ability to induce siderophore production in microorganisms, a well-recognized benefit of co-culture (47). This could improve heterologous iron availability to ' $\mathrm{Ca}$. $\mathrm{L}$. asiaticus', because the presence of high-affinity Fe chelators (e.g., siderophores) in the reduced ' $\mathrm{Ca}$. L. asiaticus' genome (13) is not indicated $(5,53)$. Juice-containing media were selected because citrus juice, a more-easily reproducible and obtainable citrus extract, was hypothesized to help maintain viability by providing many of the same nutrients available to ' $\mathrm{Ca}$. L. asiaticus' in the phloem (22). Fastidious bacteria often prefer dilute nutrient media (54); therefore, diluted versions of the media were tested.

Results show that citrus-juice-containing media sustain ' $\mathrm{Ca}$. L. asiaticus' cell viability for much longer than media without juice. ' $C a$. L. asiaticus' cell viability was sustained without transfer to fresh media throughout the 18-day time-series experiments as well as the 2-month biofilm and planktonic fraction experiments. In previous research, cells were passaged at 10 days $(9,42)$, though the percent viability of those cells prior to passage was not reported. Although the possibility of active growth of ' $\mathrm{Ca}$. L. asiaticus' in the experiments presented here cannot be excluded, the maximum observed increase in ' $\mathrm{Ca}$. L. asiaticus' copy number was low, 5 to 15 times relative to the initial concentration. Because 'Ca. L. asiaticus' may grow by septate division (9), it can

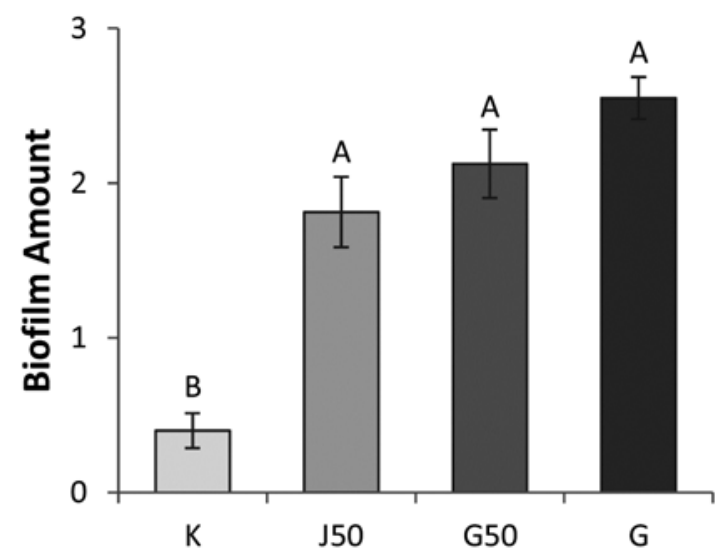

Fig. 5. Relative quantification of biofilm formation. Values are mean \pm standard error of biofilm thickness in flasks based on the following qualitative scale: $0=$ none, $1=$ trace, $2=$ medium, and $3=$ thick. Samples $\left(n_{\mathrm{K}, \mathrm{G}}=16\right.$ and $n_{\mathrm{J} 50, \mathrm{G} 50}=20$ ) are from experiments 6 to 13 and 16 to 17 . Different letters indicate significant differences according to Kruskal-Wallis and WilcoxonMann-Whitney rank-sum post-hoc tests $(P<0.05)$.

TABLE 3. Sugars and other metabolites detected in different media utilized in this study

\begin{tabular}{|c|c|c|c|c|c|}
\hline \multirow[b]{2}{*}{ Compound $^{\mathrm{x}}$} & \multirow[b]{2}{*}{$\mathrm{RT}^{\mathrm{y}}$} & \multicolumn{4}{|c|}{ Concentration in each media $(\mathrm{mM})^{\mathrm{z}}$} \\
\hline & & $\mathrm{K}$ & $\mathrm{J} 50$ & G50 & G \\
\hline Fructose & 18.45 & ND & $5.74 \pm 0.43 c$ & $54.98 \pm 3.26 \mathrm{~b}$ & $119.67 \pm 10.31 \mathrm{a}$ \\
\hline Glucose & 18.86 & ND & $7.12 \pm 0.51 \mathrm{c}$ & $56.97 \pm 4.26 b$ & $140.42 \pm 20.00 \mathrm{a}$ \\
\hline Inositol & 21.51 & ND & $3.18 \pm 0.11 \mathrm{a}$ & $3.32 \pm 2.28 \mathrm{a}$ & $4.46 \pm 1.39 \mathrm{a}$ \\
\hline Quinic acid & 18.20 & ND & ND & $0.46 \pm 0.68 \mathrm{a}$ & $0.15 \pm 0.01 \mathrm{a}$ \\
\hline Sucrose & 27.02 & ND & $5.9 \pm 1.7 \mathrm{c}$ & $27.90 \pm 15.92 \mathrm{ab}$ & $60.45 \pm 1.14 \mathrm{a}$ \\
\hline
\end{tabular}

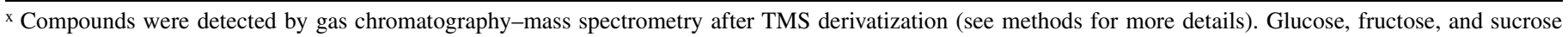
were quantified using external standard, while quinic acid and inositol were estimated relative to glucose.

y Retention time.

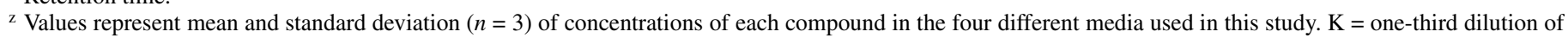
King's B medium; J20, J24, J25, and J50 = K combined with 20, 24, 25, and 50\% juice (from infected fruit), respectively; G50 = equal parts K and commercial grapefruit juice; and $\mathrm{G}=100 \%$ commercial grapefruit juice. Different letters in the same row indicate significant difference $(P<0.05)$ according to one-way analysis of variance and Tukey's test. ND = nondetectable, or below detection limit. 
be speculated that the observed increases in ' $\mathrm{Ca}$. L. asiaticus' concentration indicate that cells are attempting to divide but require some missing condition or conditions that prevent exponential growth. Similar, reproducible viability trends between J50 and $\mathrm{G} 50$ or $\mathrm{G}$ media indicate that commercial grapefruit juice purchased at different times is a sufficiently standardized replacement for the harder-to-obtain and more variable pomelo juice.

' $C a$. L. asiaticus' in media containing juice also showed evidence of a cyclical growth trend, where viability alternately increases and decreases over time in a sinusoidal fashion, generally for the duration of the experiments. The variable starting concentration of ' $\mathrm{Ca}$. L. asiaticus' cells does not appear to affect these trends. Cyclical or oscillating growth is a feature of bacterial populations attributable to either external (e.g., nutrient inputs or temperature changes) or internal (e.g., changes in readily utilizable substrate) system fluctuations (57). In a closed system, fluctuations are limited to continual organic matter decomposition and release of nutrients from dead cells $(44,57)$. In this study, cyclical growth may be evidence of the latter fluctuation, a phenomenon known as "cryptic growth." Cryptic growth (40) is a secondary growth phase in which cells grow by utilizing lysis
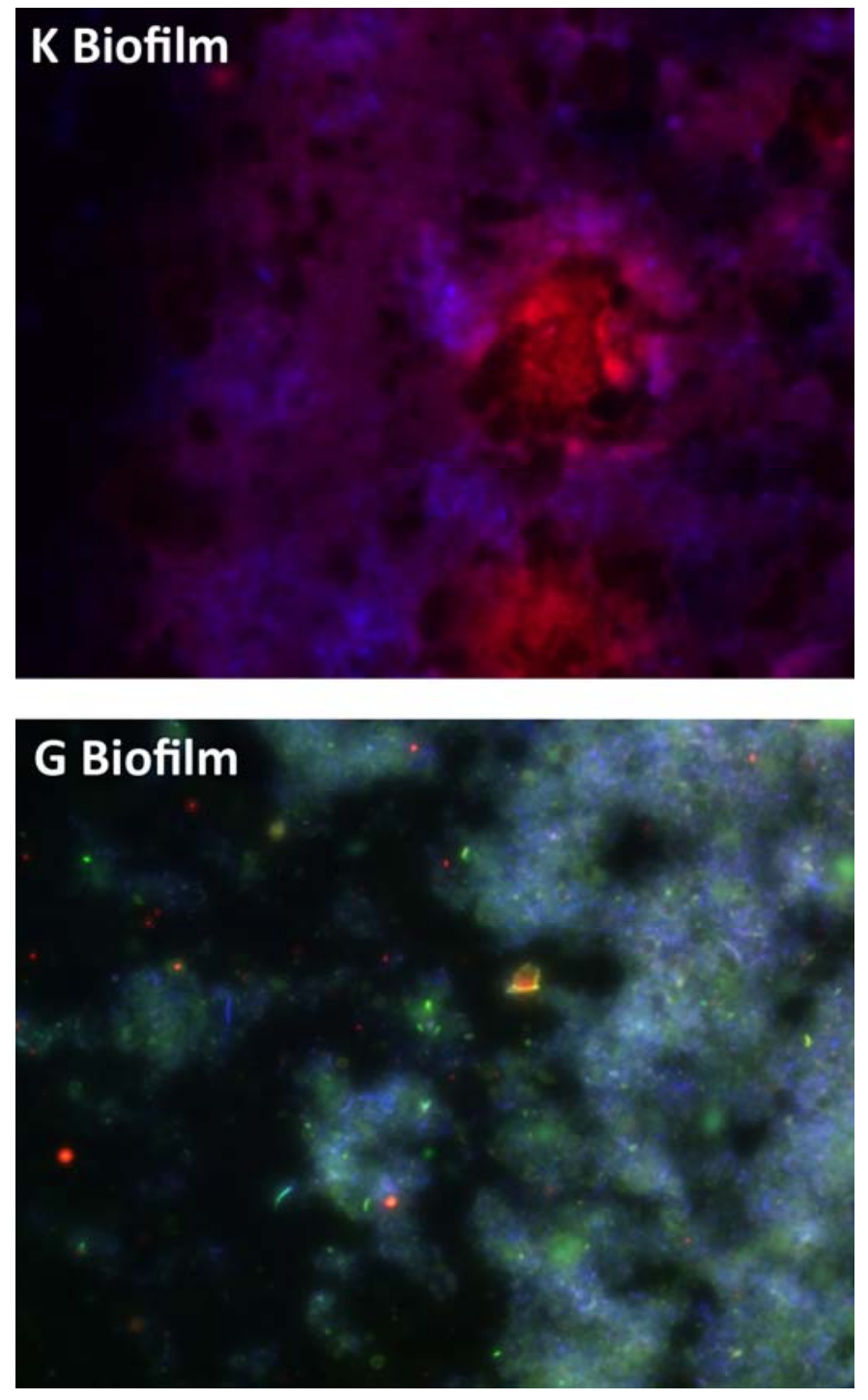

Fig. 6. Fluorescent microscopy of biofilms formed in different culture media. Images $(\times 40)$ are of stained bacterial biofilms grown on slides using experiment 16 inoculum. Biofilm formation occurred at the air-liquid interface of glass slides incubated for $\approx 2$ months in $\mathrm{K}$ medium or $\mathrm{G}$ medium containing 'Candidatus Liberibacter asiaticus' inoculum. Figure appears in color online (green $=$ live cells; red $=$ dead cells; and blue = exopolysaccharides $)$. products from dead cells, observed in both monocultures $(12,30$, 31 ) and batch cultures $(19,37)$. Cryptic growth is not inherently cyclical but cyclical cryptic growth has been observed (14).

Cryptic growth is more likely to occur in a significant or detectable capacity when cells are under starvation conditions $(12,33,56)$ and 90 to $99 \%$ of cells have died $(56)$, presumably due to lack of nutrients. Accordantly, ' $\mathrm{Ca}$. L. asiaticus' cell viability curves in the present experiments often showed a high percent viability loss between oscillation maxima and minima, because media are likely limited in essential components, considering that ' $C a$. L. asiaticus' nutritional requirements remain unclear. The presence of other bacteria in ' $\mathrm{Ca}$. L. asiaticus' cultures, indicated here by metagenomic sequencing results, could further exaggerate starvation conditions and contribute to viability fluctuations. In a co-culture model of copiotrophic and oligotrophic bacteria, both groups oscillated in time as availability of the shared substrate changed (58). Oligotrophs require poor yet precise nutrient conditions to allow them a competitive advantage over copiotrophs (43). Therefore, modeled population oscillations of these groups are inverse to each other (58), a dynamic also observed between bacteria and bacteriophages (2). Interestingly, ' $\mathrm{Ca}$. L. asiaticus' has two prophages that can undergo lytic cycle activation in plant hosts to produce phage particles (59). ' $\mathrm{Ca}$. L. asiaticus' may function in a similar way if interacting with other populations of bacteria (or phages), where opposite trophic strategies produce fluctuating levels of substrate which, in turn, yield fluctuating bacterial populations.

The previously reported co-culture of ' $\mathrm{Ca}$. L. asiaticus' with $P$. acnes (9) provides evidence that co-culture may serve a useful function in culture of ' $\mathrm{Ca}$. L. asiaticus'. Among other possible benefits, $P$. acnes produces propionic acid (32), which would reduce the media $\mathrm{pH}$. The most successful culture media tested in

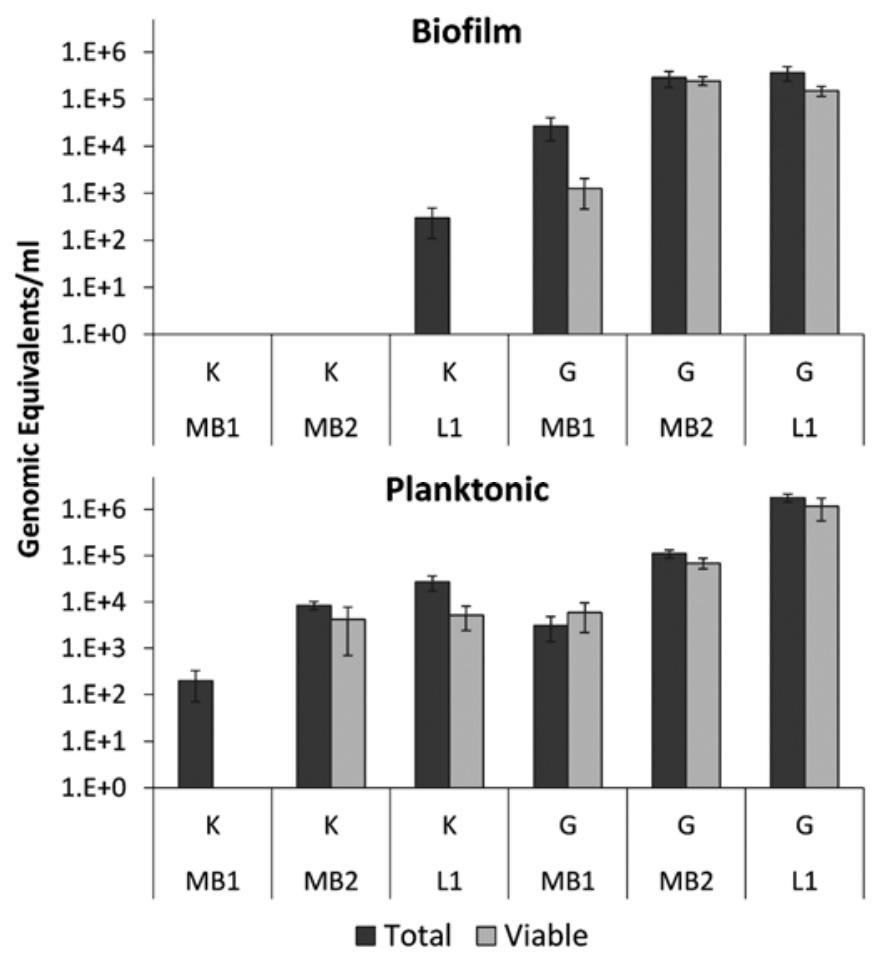

Fig. 7. Population of 'Candidatus Liberibacter asiaticus' in biofilm and planktonic fractions. Values are ' $\mathrm{Ca}$. L. asiaticus' concentrations (mean \pm standard error) in biofilm and planktonic suspensions collected from time series experiment flasks after end of experiments. Fruit cultivar used in each experiment is indicated: $\mathrm{MB}=$ Mato Buntan and $\mathrm{L}=$ Liane. Samples from experiment 6 (MB1, initiated 11 September 2011) were collected after $\approx 4$ months; samples from experiments 16 and 17 (L1, MB2, initiated 5 September 2012) were collected after $\approx 2$ months. 
the present study contained citrus juice, which significantly acidified the media. ' $C a$. L. asiaticus' appears to benefit from low $\mathrm{pH}$ culture conditions. The presence of the metal regulatory system phoP- $Q$ in the ' $C a$. L. asiaticus' genome (10) suggests that this bacterium can tolerate the oxidative stress or low $\mathrm{pH}$ conditions $(20,28,29)$ of juice-containing media, while other bacteria are inhibited. Additionally, though the co-culture of ' $\mathrm{Ca}$. L. asiaticus' $-P$. acnes grows better under microaerophilic conditions (9), this atmosphere was perhaps needed only by the aerotolerant, anaerobic $P$. acnes. Though well-characterized genera in the family Rhizobiaceae (Agrobacterium, Rhizobium, and Sinorhizobium) are aerobic, the ' $\mathrm{Ca}$. L. asiaticus' genome contains limited evidence for aerobic respiration (13). Results from the present study indicate that ' $\mathrm{Ca}$. L. asiaticus' is at least aerotolerant.

'Ca. L. asiaticus' inoculum source. Previous studies on the culture of ' $\mathrm{Ca}$. L. asiaticus' utilized inoculum derived from leaf midveins and petioles (42) or phloem tissue (9). However, reliably obtaining viable ' $\mathrm{Ca}$. L. asiaticus' inoculum from leaves and petioles may be difficult. Though microscopy has shown that ' $\mathrm{Ca}$. L. asiaticus' cell quantity is inversely correlated to leaf symptomatology, ' $C a$. L. asiaticus' DNA can be detected in all stages of infection, suggesting that cells in highly diseased tissues may be nonviable (15). High concentrations of ' $\mathrm{Ca}$. L. asiaticus' cells in the seed coats and peduncle of fruit from infected citrus trees $(21,49)$ further indicate that regions of the fruit containing vascular tissues could be a good source of inoculum. Because variable seed maturity sometimes made it difficult to separate the seed coat, entire seed were used to create a ' $\mathrm{Ca}$. L. asiaticus' inoculum, incorporating the seed coat as the inoculum source. Though the $100-\mu \mathrm{m}$ filter used to remove seed particles for inoculum preparation may not remove all particles, the effect of any remaining particle-associated ' $\mathrm{Ca}$. L. asiaticus' would be even across treatments, eliminating any potential bias.

Monitoring the seed concentrations of ' $\mathrm{Ca}$. L. asiaticus' from one pomelo tree over the course of a year shows that percent viability remains fairly steady, averaging $16 \%$ (range of 4 to $34 \%$ ), comparable with a previous study showing 17 to $31 \%$ viability in symptomatic citrus tissues (51). However, a peak in total and viable cell concentrations occurred from September to October, likely reflecting seasonal changes in the rate of phloem transport to the seed vascular bundles. In Spanish Marisol clementine fruit for which the end of anthesis occurred 30 March, maximum phloem cross-sectional area and specific mass transfer in the pedicel occurred mid-June (16). End of anthesis for most Florida citrus also typically occurs around the end of March, with harvest dates from October to June. Because ' $C a$. L. asiaticus' is phloem limited, the phloem provides the only means of bacterial transfer to the seed; therefore, it can be hypothesized that full phloem development occurs prior to peak transfer. Assuming a similar maturation cycle, Mato Buntan pomelo phloem development would be completed several months prior to peak ' $\mathrm{Ca}$. L. asiaticus' concentrations. The process of fruit abscission, which slowly cuts off the vascular nutrient supply to the fruit prior to harvest, may explain the observed decreases in ' $\mathrm{Ca}$. L. asiaticus' populations in the seed from December to April.

Citrus seed bacterial inoculum composition. Because seed of fruit from ' $\mathrm{Ca}$. L. asiaticus'-infected trees have not been used as an inoculum source in published studies of ' $\mathrm{Ca}$. L. asiaticus' culture $(9,42)$, the present study sought to further characterize the seed-derived ' $C a$. L. asiaticus' inoculum via next-generation sequencing. Despite high percentages of reads of chloroplast and mitochondrial origin, a common difficulty when amplifying plant bacterial communities (38), sufficient bacterial reads were obtained for accurate identification of the major genera. As anticipated, ' $C a$. L. asiaticus' was the primary bacterial component of the seed inoculum (54\%), as shown previously for leaf midribs (41), phloem (52), and roots (50) of ' $\mathrm{Ca}$. L. asiaticus'-infected citrus plants. There were also significant amounts of other bac- teria in the seed, including Flavobacterium, Pedobacter, and Bacillus spp. Flavobacterium and Bacillus are two of the most frequently isolated culturable bacterial genera in seed $(25,34)$ and their families, Flavobacteriaceae and Bacillaceae, respectively, were detected in ' $\mathrm{Ca}$. L. asiaticus'-infected citrus leaf midribs (41). Also, it has been shown that relative abundance of bacteria in the phylum Bacteroidetes, to which the genera Flavobacterium and Pedobacter belong, is significantly higher in ' $\mathrm{Ca}$. L. asiaticus'-infected than uninfected citrus roots (50). The presence of other bacteria besides ' $\mathrm{Ca}$. L. asiaticus' in the inoculum is significant. If cultured alongside ' $C a$. L. asiaticus' in vitro, other microflora could contribute metabolic byproducts, siderophores, quorum-sensing molecules, or other environment-modifying components that could affect $(47,54)$, either positively or negatively, the culture of ' $\mathrm{Ca}$. L. asiaticus' from seed inoculum.

Bacterial biofilm and planktonic fraction characterization. Fluorescent microscopy indicated that a true biofilm was formed during these experiments. Further biofilm characterizations via ' $C a$. L. asiaticus'-specific qPCR and sequencing of the bacterial metagenome indicated that ' $\mathrm{Ca}$. L. asiaticus' is present in the biofilm found in juice-containing media but it is not the predominant bacterium. The same was true for the bacterial community in the planktonic fraction of the juice-containing media, which contained the same bacterial genera but at different relative abundances. Interestingly, the biofilm and planktonic fractions from medium K cultures, which did not prolong viability of ' $\mathrm{Ca}$. L. asiaticus', had only a monoculture of Bacillus. The diverse bacterial community supported by media containing juice may help promote the prolonged viability and growth of ' $\mathrm{Ca}$. L. asiaticus' through physical protection or the production of environment-modifying components, as previously discussed, but further research is necessary to confirm this.

Media characteristics supporting ' $\boldsymbol{C} \boldsymbol{a}$. L. asiaticus' viability. Comparison of media chemical compositions showed that media that contained citrus juice and supported ' $C a$. L. asiaticus' viability were more abundant in essential mineral elements. The only high-affinity mineral element transport systems encoded in the reduced ' $C a$. L. asiaticus' genome are for $\mathrm{Zn}$ and $\mathrm{Mn}(10,53)$. This indicates that ' $C a$. L. asiaticus' may have a special requirement for $\mathrm{Zn}$ and $\mathrm{Mn}$, both of which are limited in $\mathrm{K}$ medium. Only $\mathrm{Na}$, an element nonessential for bacterial growth, and $\mathrm{S}$, abundant in amino acids (e.g., methionine) in the $\mathrm{K}$ medium carbon source, were reduced in juice-containing media. Amino acids for which ' $\mathrm{Ca}$. L. asiaticus' is proposed to be auxotrophic (tryptophan, tyrosine, leucine, isoleucine, and valine) (13) were at similar concentrations among all media, satisfying basic growth requirements. ' $\mathrm{Ca}$. L. asiaticus' is able to utilize all the amino acids found in higher abundance in $\mathrm{G}$ than $\mathrm{K}$ (alanine, aspartate, serine, and proline) (13). Sugars (fructose, glucose, inositol, and sucrose), some amino acids ( $\gamma$-aminobutyric acid), and organic acids (succinic, malic, citric, and quinic acids) were nondetectable in $\mathrm{K}$; therefore, their role in ' $C a$. L. asiaticus' viability needs further examination. Juice from infected (pomelo) and healthy (grapefruit) fruit, although not directly comparable, differ in some components previously identified as deficient in ' $\mathrm{Ca}$. L. asiaticus'-infected trees. The significant depletion of P in medium J50 is likely symptomatic of ' $\mathrm{Ca}$. L. asiaticus' infection in the source material, because a recent study found a $35 \%$ reduction in $\mathrm{P}$ in 'Ca. L. asiaticus'-infected versus healthy citrus trees (60). Deficiencies found here in sugars (glucose and sucrose) and amino acids (proline) in juice from infected fruit corroborate previous reports on symptomatic citrus fruit $(1,39,45)$, which may indicate a need of ' $\mathrm{Ca}$. L. asiaticus' for these components.

Conclusions. This study demonstrates that culture media containing commercially available citrus juice are superior for prolonging the viability of ' $\mathrm{Ca}$. L. asiaticus' in vitro. Conditions such as lower $\mathrm{pH}$, presence of sugars, abundance of specific mineral elements and amino acids, and, possibly, the presence of 
other microflora may contribute to ' $\mathrm{Ca}$. L. asiaticus' viability. This study also shows that citrus seed coats provide a good source of viable ' $\mathrm{Ca}$. L. asiaticus' inoculum that can be used for further exploration of ' $\mathrm{Ca}$. L. asiaticus' culture. This information should be taken into consideration when designing possible culture media for ' $\mathrm{Ca}$. L. asiaticus'.

\section{ACKNOWLEDGMENTS}

Funding was provided by the Citrus Research and Development Foundation, Inc. (project number 307) and the Auburn University College of Sciences and Mathematics Undergraduate Research Fellowship. We thank K. Sims for providing citrus samples and experimental recommendations, M. Newman for help in setting up and operating the Illumina MiSeq, P. Cobine and J. Oliver for assistance with ICP-OES, F. Navarrete for helpful discussions on ' $\mathrm{Ca}$. L. asiaticus' genetics, and J. Havird and J. Oliver for manuscript editing.

\section{LITERATURE CITED}

1. Baldwin, E., Plotto, A., Manthey, J., McCollum, G., Bai, J. H., Irey, M., Cameron, R., and Luzio, G. 2010. Effect of Liberibacter infection (huanglongbing disease) of citrus on orange fruit physiology and fruit/ fruit juice quality: Chemical and physical analyses. J. Agric. Food Chem. 58:1247-1262.

2. Bohannan, B. J. M., and Lenski, R. E. 1999. Effect of prey heterogeneity on the response of a model food chain to resource enrichment. Am. Nat. 153:73-82.

3. Bové, J. M. 2006. Huanglongbing: A destructive, newly-emerging, century-old disease of citrus. J. Plant Pathol. 88:7-37.

4. Caporaso, J. G., Lauber, C. L., Walters, W. A., Berg-Lyons, D., Lozupone, C. A., Turnbaugh, P. J., Fierer, N., and Knight, R. 2011. Global patterns of $16 \mathrm{~S}$ rRNA diversity at a depth of millions of sequences per sample. Proc. Natl. Acad. Sci. USA 108:4516-4522.

5. Chavez, G. A. T., Zaini, P. A., and da Silva, A. M. Iron as a regulator of virulence in plant pathogenic bacteria. In: Virulence Mechanisms of Plant Pathogenic Bacteria. N. Wang, L. De La Fuente, J. Jones, J. Ham, F. White, G. Sundin, S. Hogenhout, and C. Roper, eds. American Phytopathological Society, St. Paul, MN. (In press.)

6. Chen, W. P., Yang, X. Y., Hegeman, A. D., Gray, W. M., and Cohen, J. D. 2010. Microscale analysis of amino acids using gas chromatography-mass spectrometry after methyl chloroformate derivatization. J. Chromatogr. B 878:2199-2208.

7. Cobine, P. A., Cruz, L. F., Navarrete, F., Duncan, D., Tygart, M., and De La Fuente, L. 2013. Xylella fastidiosa differentially accumulates mineral elements in biofilm and planktonic cells. PLoS One 8:e54936.

8. Cole, J. R., Wang, Q., Cardenas, E., Fish, J., Chai, B., Farris, R. J., Kulam-Syed-Mohideen, A. S., McGarrell, D. M., Marsh, T., Garrity, G. M., and Tiedje, J. M. 2009. The Ribosomal Database Project: Improved alignments and new tools for rRNA analysis. Nucleic Acids Res. 37:D141-D145.

9. Davis, M. J., Mondal, S. N., Chen, H. Q., Rogers, M. E., and BrIansky, R. H. 2008. Co-cultivation of 'Candidatus Liberibacter asiaticus' with actinobacteria from citrus with huanglongbing. Plant Dis. 92:1547-1550.

10. De La Fuente, L., Navarrete, F., Oliver, J. E., Cruz, L. F., and Cobine, P. A. The influence of metal elements on virulence in plant pathogenic bacteria. In: Virulence Mechanisms of Plant Pathogenic Bacteria. N. Wang, L. De La Fuente, J. Jones, J. Ham, F. White, G. Sundin, S. Hogenhout, and C. Roper, eds. American Phytopathological Society Press, St. Paul, MN. (In press.)

11. Doyle, J., and Doyle, J. L. 1987. Genomic plant DNA preparation from fresh tissue-CTAB method. Phytochem. Bull. 19:11-15.

12. Druilhet, R. E., and Sobek, J. M. 1976. Starvation survival of Salmonella enteritidis. J. Bacteriol. 125:119-124.

13. Duan, Y. P., Zhou, L. J., Hall, D. G., Li, W. B., Doddapaneni, H., Lin, H., Liu, L., Vahling, C. M., Gabriel, D. W., Williams, K. P., Dickerman, A., Sun, Y. J., and Gottwald, T. 2009. Complete genome sequence of citrus huanglongbing bacterium, 'Candidatus Liberibacter asiaticus' obtained through metagenomics. Mol. Plant-Microbe Interact. 22:1011-1020.

14. Fernandez, J. L., and Simpson, W. J. 1994. Cyclic growth of lactobacilli in beer. J. Appl. Bacteriol. 77:635-638

15. Folimonova, S. Y., and Achor, D. S. 2010. Early events of citrus greening (huanglongbing) disease development at the ultrastructural level. Phytopathology 100:949-958.

16. Garcia-Luis, A., Oliveira, M. E. M., Bordon, Y., Siqueira, D. L., Tominaga, S., and Guardiola, J. L. 2002. Dry matter accumulation in citrus fruit is not limited by transport capacity of the pedicel. Ann. Bot. 90:755-764.
17. Gottwald, T. R. 2010. Current epidemiological understanding of citrus huanglongbing. Annu. Rev. Phytopathol. 48:119-139.

18. Gullberg, J., Jonsson, P., Nordstrom, A., Sjostrom, M., and Moritz, T. 2004. Design of experiments: An efficient strategy to identify factors influencing extraction and derivatization of Arabidopsis thaliana samples in metabolomic studies with gas chromatography/mass spectrometry. Anal. Biochem. 331:283-295.

19. Hao, X. D., Wang, Q. L., Zhu, J. Y., and Van Loosdrecht, M. C. M. 2010. Microbiological endogenous processes in biological wastewater treatment systems. Crit. Rev. Environ. Sci. Technol. 40:239-265.

20. Haque, M. M., Hirata, H., and Tsuyumu, S. 2012. Role of PhoP-PhoQ two-component system in pellicle formation, virulence and survival in harsh environments of Dickeya dadantii 3937. J. Gen. Plant Pathol. 78:176-189.

21. Hilf, M. E. 2011. Colonization of citrus seed coats by 'Candidatus Liberibacter asiaticus': Implications for seed transmission of the bacterium. Phytopathology 101:1242-1250.

22. Huang, T. B., Darnell, R. L., and Koch, K. E. 1992. Water and carbon budgets of developing citrus fruit. J. Am. Soc. Hortic. Sci. 117:287-293.

23. Jagoueix, S., Bové, J. M., and Garnier, M. 1994. The phloem-limited bacterium of greening disease of citrus is a member of the alphasubdivision of the proteobacteria. Int. J. Syst. Bacteriol. 44:379-386.

24. King, E. O., Ward, M. K., and Raney, D. E. 1954. Two simple media for the demonstration of pyocyanin and fluorescein. J. Lab. Clin. Med. 44:301-307.

25. Kremer, R. J. 1987. Identity and properties of bacteria inhabiting seeds of selected broadleaf weed species. Microbiol. Ecol. 14:29-37.

26. Li, W. B., Hartung, J. S., and Levy, L. 2006. Quantitative real-time PCR for detection and identification of 'Candidatus Liberibacter species' associated with citrus huanglongbing. J. Microbiol. Methods 66:104-115.

27. Li, W. B., Li, D. Y., Twieg, E., Hartung, J. S., and Levy, L. 2008. Optimized quantification of unculturable 'Candidatus Liberibacter spp.' in host plants using real-time PCR. Plant Dis. 92:854-861.

28. Llama-Palacios, A., Lopez-Solanilla, E., Poza-Carrion, C., GarciaOlmedo, F., and Rodriguez-Palenzuela, P. 2003. The Erwinia chrysanthemi phoP-phoQ operon plays an important role in growth at low $\mathrm{pH}$, virulence and bacterial survival in plant tissue. Mol. Microbiol. 49:347357.

29. Llama-Palacios, A., Lopez-Solanilla, E., and Rodriguez-Palenzuela, P. 2005. Role of the PhoP-PhoQ system in the virulence of Erwinia chrysanthemi strain 3937: Involvement in sensitivity to plant antimicrobial peptides, survival at acid $\mathrm{Hh}$, and regulation of pectolytic enzymes. J. Bacteriol. 187:2157-2162.

30. Mason, C. A., and Hamer, G. 1987. Cryptic growth in Klebsiella pneumoniae. Appl. Microbiol. Biot. 25:577-584.

31. McAlister, M. B., Kulakov, L. A., O'Hanlon, J. F., Larkin, M. J., and Ogden, K. L. 2002. Survival and nutritional requirements of three bacteria isolated from ultrapure water. J. Ind. Microbiol. Biot. 29:75-82.

32. Meile, L., Dasen, G., Miescher, S., Stierli, M., and Teuber, R. 1999. Classification of propionic acid bacteria and approaches to applied genetics. Lait 79:71-78.

33. Mukamolova, G. V., Yanopolskaya, N. D., Votyakova, T. V., Popov, V. I., Kaprelyants, A. S., and Kell, D. B. 1995. Biochemical changes accompanying the long-term starvation of Micrococcus luteus cells in spent growth medium. Arch. Microbiol. 163:373-379.

34. Mundt, J. O., and Hinkle, N. F. 1976. Bacteria within ovules and seeds. Appl. Environ. Microbiol. 32:694-698.

35. Nocker, A., and Camper, A. K. 2006. Selective removal of DNA from dead cells of mixed bacterial communities by use of ethidium monoazide. Appl. Environ. Microbiol. 72:1997-2004.

36. Nogva, H. K., Dromtorp, S. M., Nissen, H., and Rudi, K. 2003. Ethidium monoazide for DNA-based differentiation of viable and dead bacteria by 5'-nuclease PCR. Biotechniques 34:804-813.

37. Ramakrishna, D. M., and Viraraghavan, T. 2005. Strategies for sludge minimization in activated sludge process-a review. Fresenius Environ. Bull. 14:2-12.

38. Rastogi, G., Tech, J. J., Coaker, G. L., and Leveau, J. H. J. 2010. A PCRbased toolbox for the culture-independent quantification of total bacterial abundances in plant environments. J. Microbiol. Methods 83:127-132.

39. Rosales, R., and Burns, J. K. 2011. Phytohormone changes and carbohydrate status in sweet orange fruit from huanglongbing-infected trees. J. Plant Growth Regul. 30:312-321.

40. Ryan, F. J. 1955. Spontaneous mutation in non-dividing bacteria. Genetics 40:726-738.

41. Sagaram, U. S., DeAngelis, K. M., Trivedi, P., Andersen, G. L., Lu, S. E., and Wang, N. 2009. Bacterial diversity analysis of huanglongbing pathogen-infected citrus, using PhyloChip arrays and 16S rRNA gene clone library sequencing. Appl. Environ. Microbiol. 75:1566-1574.

42. Sechler, A., Schuenzel, E. L., Cooke, P., Donnua, S., Thaveechai, N., Postnikova, E., Stone, A. L., Schneider, W. L., Damsteegt, V. D., and 
Schaad, N. W. 2009. Cultivation of 'Candidatus Liberibacter asiaticus', 'Ca. L. africanus', and ' $\mathrm{Ca}$. L. americanus' associated with huanglongbing. Phytopathology 99:480-486.

43. Semenov, A. M. 1991. Physiological bases of oligotrophy of microorganisms and the concept of microbial community. Microbiol. Ecol. 22:239-247.

44. Semenov, A. V., Franz, E., and van Bruggen, A. H. C. 2010. COLIWAVE a simulation model for survival of $E$. coli $\mathrm{O} 157: \mathrm{H} 7$ in dairy manure and manure-amended soil. Ecol. Model. 221:599-609.

45. Slisz, A. M., Breksa, A. P., Mishchuk, D. O., McCollum, G., and Slupsky, C. M. 2012. Metabolomic analysis of citrus infection by 'Candidatus Liberibacter' reveals insight into pathogenicity. J. Proteome Res. 11:42234230.

46. Smart, K. F., Aggio, R. B. M., Van Houtte, J. R., and Villas-Boas, S. G. 2010. Analytical platform for metabolome analysis of microbial cells using methyl chloroformate derivatization followed by gas chromatography-mass spectrometry. Nat. Protocols 5:1709-1729.

47. Stewart, E. J. 2012. Growing unculturable bacteria. J. Bacteriol. 194:4151-4160.

48. Stokstad, E. 2012. Dread citrus disease turns up in California, Texas. Science 336:283-284.

49. Tatineni, S., Sagaram, U. S., Gowda, S., Robertson, C. J., Dawson, W. O., Iwanami, T., and Wang, N. 2008. In planta distribution of 'Candidatus Liberibacter asiaticus' as revealed by polymerase chain reaction (PCR) and real-time PCR. Phytopathology 98:592-599.

50. Trivedi, P., Duan, Y. P., and Wang, N. A. 2010. Huanglongbing, a systemic disease, restructures the bacterial community associated with citrus roots. Appl. Environ. Microbiol. 76:3427-3436.

51. Trivedi, P., Sagaram, U. S., Kim, J. S., Brlansky, R. H., Rogers, M. E., Stelinski, L. L., Oswalt, C., and Wang, N. 2009. Quantification of viable 'Candidatus Liberibacter asiaticus' in hosts using quantitative PCR with the aid of ethidium monoazide (EMA). Eur. J. Plant Pathol. 124:553-563.

52. Tyler, H. L., Roesch, L. F. W., Gowda, S., Dawson, W. O., and Triplett, E. W. 2009. Confirmation of the sequence of 'Candidatus Liberibacter asiaticus' and assessment of microbial diversity in huanglongbinginfected citrus phloem using a metagenomic approach. Mol. PlantMicrobe Interact. 22:1624-1634.

53. Vahling-Armstrong, C. M., Zhou, H. S., Benyon, L., Morgan, J. K., and Duan, Y. P. 2012. Two plant bacteria, S. meliloti and Ca. Liberibacter asiaticus, share functional znuABC homologues that encode for a high affinity zinc uptake system. PLoS One 7:e37340.

54. Vartoukian, S. R., Palmer, R. M., and Wade, W. G. 2010. Strategies for culture of 'unculturable' bacteria. FEMS Microbiol. Lett. 309:1-7.

55. Villas-Bôas, S. G., Noel, S., Lane, G. A., Attwood, G., and Cookson, A. 2006. Extracellular metabolomics: A metabolic footprinting approach to assess fiber degradation in complex media. Anal. Biochem. 349:297-305.

56. Watson, S. P., Clements, M. O., and Foster, S. J. 1998. Characterization of the starvation-survival response of Staphylococcus aureus. J. Bacteriol. 180:1750-1758.

57. Zelenev, V. V., van Bruggen, A. H., and Semenov, A. M. 2000. "BACWAVE," a spatial-temporal model for traveling waves of bacterial populations in response to a moving carbon source in soil. Microb. Ecol. 40:260-272.

58. Zelenev, V. V., van Bruggen, A. H. C., and Semenov, A. M. 2005. Modeling wave-like dynamics of oligotrophic and copiotrophic bacteria along wheat roots in response to nutrient input from a growing root tip. Ecol. Model. 188:404-417.

59. Zhang, S. J., Flores-Cruz, Z., Zhou, L. J., Kang, B. H., Fleites, L. A., Gooch, M. D., Wulff, N. A., Davis, M. J., Duan, Y. P., and Gabriel, D. W. 2011. 'Ca. Liberibacter asiaticus' carries an excision plasmid prophage and a chromosomally integrated prophage that becomes lytic in plant infections. Mol. Plant-Microbe Interact. 24:458-468.

60. Zhao, H., Sun, R., Albrecht, U., Padmanabhan, C., Wang, A., Coffey, M. D., Girke, T., Wang, Z., Close, T. J., Roose, M., Yokomi, R. K., Folimonova, S., Vidalakis, G., Rouse, R., Bowman, K. D., and Jin, H. 2013. Small RNA profiling reveals phosphorus deficiency as a contributing factor in symptom expression for citrus huanglongbing disease. Mol. Plant $6: 301-310$ 